\title{
OPEN Serotonin deficiency induced after brain maturation rescues consequences of early life adversity
}

\author{
B. Aboagye ${ }^{1,7}$, T. Weber ${ }^{4,5}$, H. L. Merdian ${ }^{6}$, D. Bartsch ${ }^{4}$, K. P. Lesch ${ }^{1,2,3,8 \bowtie}$ \& J. Waider ${ }^{1,8 凶}$
}

Brain serotonin (5-HT) system dysfunction is implicated in depressive disorders and acute depletion of 5-HT precursor tryptophan has frequently been used to model the influence of 5-HT deficiency on emotion regulation. Tamoxifen (TAM)-induced Cre/loxP-mediated inactivation of the tryptophan hydroxylase-2 gene (Tph2) was used to investigate the effects of provoked 5-HT deficiency in adult mice (Tph2 icKO) previously subjected to maternal separation (MS). The efficiency of Tph2 inactivation was validated by immunohistochemistry and HPLC. The impact of Tph2 icKO in interaction with MS stress (Tph2 icKO $\times$ MS) on physiological parameters, emotional behavior and expression of 5-HT system-related marker genes were assessed. Tph2 icKO mice displayed a significant reduction in 5-HT immunoreactive cells and 5-HT concentrations in the rostral raphe region within four weeks following TAM treatment. Tph2 icKO and MS differentially affected food and water intake, locomotor activity as well as panic-like escape behavior. Tph2 icKO prevented the adverse effects of MS stress and altered the expression of the genes previously linked to stress and emotionality. In conclusion, an experimental model was established to study the behavioral and neurobiological consequences of 5-HT deficiency in adulthood in interaction with early-life adversity potentially affecting brain development and the pathogenesis of depressive disorders.

Brain serotonin (5-HT) system dysfunction is implicated in disorders of emotion regulation, such as anxiety and depression, viewed as multifactorial conditions influenced by multiple gene-by-gene and gene-by-environment interactions ${ }^{1}$. Previous research identified genetic variants regulating the expression of the gene encoding the rate-limiting enzyme of neuronal serotonin (5-HT) synthesis, tryptophan hydroxylase-2 (TPH2) ${ }^{2,3}$, which converts the essential amino acid tryptophan (TRP) into 5-OH-TRP, the direct precursor of 5- $\mathrm{HT}^{4,5}$.

Depletion of TRP by dietary intervention (acute TRP depletion, ATD) has traditionally been used in assessing the influence of 5-HT deficiency on emotion dysregulation and the pathogenesis of depressive disorders. TRPfree diet produces an acute and profound reduction in brain TRP and consequently brain 5-HT synthesis ${ }^{6-8}$. ATD decreases anxiety in patients with anorexia nervosa ${ }^{9}$ and also lowered mood in healthy participants and individuals with bulimia nervosa ${ }^{10,11}$. However, the mechanisms of ATD and the impact of reduced brain 5-HT on behavior are still not well understood ${ }^{12}$. Animal model studies provide evidence for alterations in brain 5 -HT release following ATD, resulting in altered anxiety- and depression-related behavior ${ }^{13}$.

Genetic manipulation in mice, which results in embryonic inactivation of Tph2 or other 5-HT neuron development-related genes (e.g. Pet $1, \operatorname{Lm} \times 1 b$ ), provided insight into the behavioral and physiological consequences of 5-HT deficiency in the brain ${ }^{14,15}$. Several studies showed that neonates with a constitutive Tph2 inactivation present viability and growth-related problems compared to wildtype counterparts ${ }^{16,17}$. While these mice retain normal 5-HT neuron morphology and physiology, and are indistinguishable from controls in adulthood ${ }^{18,19}$, several behavioral phenotypes have been reported ${ }^{20-22}$. These phenotypes arising from lifelong Tph2 inactivation may be the consequence of impaired functioning of other relevant genes, the expression of which is, at least

\footnotetext{
${ }^{1}$ Division of Molecular Psychiatry, Laboratory of Translational Neuroscience, Center of Mental Health, University of Würzburg, Margarete-Höppel-Platz 1, 97080 Würzburg, Germany. ${ }^{2}$ Laboratory of Psychiatric Neurobiology, Institute of Molecular Medicine, I.M. Sechenov First Moscow State Medical University, Moscow, Russia. ${ }^{3}$ Department of Psychiatry and Psychology, School for Mental Health and Neuroscience (MHeNS), Maastricht University, Maastricht, The Netherlands. ${ }^{4}$ Department of Molecular Biology, Central Institute of Mental Health, Medical Faculty Mannheim, Heidelberg University, Mannheim, Germany. ${ }^{5}$ MEDIAN Clinic Wilhelmsheim, Oppenweiler, Germany. ${ }^{6}$ School of Psychology, University of Lincoln, Lincoln, UK. ${ }^{7}$ Department of Biomedical and Forensic Science, School of Biological Sciences, University of Cape Coast, Cape Coast, Ghana. ${ }^{8}$ These authors contributed equally: K.P. Lesch and J.Waider. ${ }^{\circledR}$ email: kplesch@mail.uni-wuerzburg.de; Waider_J@ukw.de
} 
partly, dependent on 5-HT during brain maturation ${ }^{23,24}$ and may result in structural and functional differences of the networks involved in emotional processing of mice lacking Tph2 ${ }^{25}$.

Here, we used Tamoxifen (TAM)-induced Cre/loxP-mediated inactivation of the Tph 2 to investigate the effects of provoked 5-HT deficiency in the modulation of emotional responses and risk for anxiety disorders and depression in interaction with environmental adversity during brain maturation in adult mice (Tph2 icKO) previously subjected to maternal separation (MS).

\section{Material and methods}

Animals. In this study only male mice were used. They were housed in groups in a controlled environment $\left(12 / 12 \mathrm{~h} \mathrm{light} / \mathrm{dark}\right.$ cycle, $21 \pm 0.5^{\circ} \mathrm{C}$ room temperature, $50 \pm 5 \%$ humidity) with food and water ad libitum. Mice were acclimatized to single housing conditions for $\geq 3$ weeks prior to behavioral experiments. Behavioral tests were performed during the light phase between 10:00 and 15:00 with a recovery period of 7 days between different tests. All in vivo animal experiments were performed in accordance with the European Parliament and Council Directive (2010/63/EU) and ARRIVE guidelines. The study was approved by the institutional review board of the University of Würzburg and the Government of Lower Franconia (55.2-2531.01-57/12).

Induction of Tph2 inactivation. For temporal and spatial control of Tph2 recombination, mice homozygous for $T p h 2$ exon five flanked by loxP-sites $\left(T p h 2^{\mathrm{f} / \mathrm{fl}}\right)$, the palindromic recognition sites of Cre recombinase ${ }^{26}$ backcrossed onto a C57Bl/6N background were crossed with Tph 2 null mutant mice (Tph $\left.2^{-/-}\right)$to generate Tph $2^{f l-}$ hemizygous mice, which lack one Tph2 allele from the beginning of their life similar to heterozygous Tph2 knockout mice $\left(T p h 2^{+-}\right)$. These mouse lines were crossed with C57Bl/6N.Tg ${ }^{\text {Tph2creERT2 }}$ transgenic mice, which express CreERT2 under the control of the murine Tph2 promoter exclusively in the raphe nuclei, to gener-

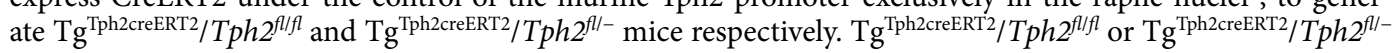
males were crossed with non-transgenic females in order to control the number of Tph2creERT2 transgenes $(n=1)$ in the animals. In order to initiate Cre/loxP-mediated recombination to generate an induced raphe nuclei specific Tph2 knockout (Tph2icKO), male Tg Tph2creERT2/Tph $2^{f l f l}$ or Tg Tph2creERT2/Tph $2^{f l-}$ mice aged $10-12$ weeks were injected twice a day for 5 consecutive days with $1 \mathrm{mg}$ of Tamoxifen (TAM; Sigma Aldrich, St. Louis, USA) ${ }^{27}$

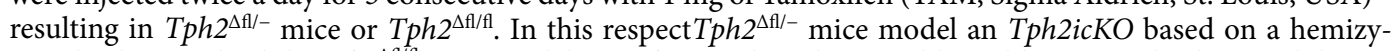
gous background, while $T p h 2^{\Delta \mathrm{f} / / \mathrm{l}}$ mice model an Tph2icKO based on a wildtype like genetic background during development. Tg Tph2creERT $/ T p h 2^{+/+}$mice injected with TAM $\left(T p h 2^{\Delta+/+}\right)$ were used as controls. Vehicle injected mice of same genotype were used as controls in the maternal separation experiments (Tph2 CON).

Immunohistochemistry. The efficacy of TAM-induced time-specific Tph2 inactivation in the brainstem raphe region was assessed by fluorescence immunohistochemistry in the 4 th and 6 th week after treatment. Thin sections $(30 \mu \mathrm{m})$ of brain of mice $\left(n=7-9 /\right.$ group) were cut on cryostat and stored at $-80{ }^{\circ} \mathrm{C}$. Frozen sections were dried for 15-20 min. An antigen retrieval was conducted as previously described ${ }^{26}$. Sections were cooled down to $40{ }^{\circ} \mathrm{C}$ and washed $3 \times 5 \mathrm{~min}$ in Tris-buffered saline (TBS). Unspecific binding sites for the antibodies were blocked for $90 \mathrm{~min}$ at room temperature (RT) with blocking solution (5\% normal goat serum, $0.25 \%$ Triton-X100 in TBS). Sections were incubated overnight with the primary antibody (1:400, goat-anti 5-HT; Immunostar; Hudson; USA) diluted in blocking solution (TBS-T) at $4{ }^{\circ} \mathrm{C}$ in a humid chamber. Following three 5 -min washing steps in TBS, sections were incubated in the dark with the respective fluorescent secondary antibodies (1:400 Cy3) diluted in blocking solution, lasting $90 \mathrm{~min}$. Sections were washed $3 \times 5 \mathrm{~min}$ in TBS. For staining of the cell nuclei, sections were treated with $300 \mu \mathrm{m}$ DAPI diluted 1:1000 in TBS for $5 \mathrm{~min}$. The number raphe neurons that were immunoreactive (ir) for 5-HT in dorsal (DRN: B6, B7) and median raphe nuclei (MRN: B5, B8, B9 $)^{28,29}$ based on cell nuclei surrounded by anti-Tph2 signal using Fiji software ${ }^{30}$ on four consecutive pictures of anterior raphe (DRN and MRN) corresponding to Bregma $-4.95 \mathrm{~mm}$ to $-4.47 \mathrm{~mm}$ spaced $180 \mu \mathrm{m}^{31}$.

Neurochemistry. For high performance liquid chromatography (HPLC), three brain regions (hippocampus, the dorsal raphe and the amygdaloid complex) were quickly dissected under a stereo microscope. For this, the brain $(n=4-7)$ was sliced with the aid of a metallic matrix, which allows sectioning at equal intervals on a cold plate. The identified regions were dissected out with a preparation spatula and kept frozen at $-80{ }^{\circ} \mathrm{C}$ until use. The brain homogenates were prepared and analyzed to standard protocols ${ }^{19,25}$.

Body weight and food intake. Body weight of mice $(n=18-25)$ used for the baseline behavioral study was measured weekly for 7 weeks starting from the first week of injection. Body-weight measurements were conducted from 10 to 11 a.m. Two weeks after the last injection, mice were single-housed and their food and water-intake was measured weekly.

Behavioral assessment. Mice were subjected to behavioral testing starting from 4 weeks after TAM injections. In the baseline study, one group of mice ( $n=13-15 /$ group) was first tested for anxiety-like behavior in the light-dark transition test (LDT), followed by an open-field test (OF) to assess locomotor activity in a novel inescapable environment ${ }^{32}$. A second group of mice $(n=7-11$ /group) was used to assess anxiety- and depressionlike behaviour including an elevated-plus maze test (EPM), sucrose preference test and lastly Porsolt swim test $(\mathrm{PST})^{33}$. Observations were recorded with VideoMot2 (TSE Systems, Bad Homburg, Germany) and later analyzed with EthoVision XT 11.5 (Noldus, Wageningen, The Netherlands). For details see supplementary methods. 
Maternal separation. In the second study, pups of the $\mathrm{Tg}^{\mathrm{Tph} 2 \mathrm{creERT}} / \mathrm{Tph} 2^{\mathrm{f} / \mathrm{fl}}$ genotype were separated on the second postnatal day (P2) from their mothers and kept in fresh cages for $3 \mathrm{~h}$ daily (between 10.00 and 13.00), for 14 consecutive days (P2-16). Ambient temperature was ensured by infrared light, positioned $70 \mathrm{~cm}$ above the cage. Non-MS mice were not separated from the dams but were handled during routine cage changes. Mice were weaned at 25 days after birth and kept in groups of 2 to 5 mice per cage and injected with either TAM (Tph $2^{\Delta f l f f}$ ) or vehicle (CON) ( $n=8-10 /$ group). After 4 weeks, mice were tested for anxiety-related behavior in the EPM, LBD and OF followed by SPT and FST for depression related behavior with 3 days inter-trial time, all tests were done as described in supplementary methods.

Quantitative real-time PCR. Quantification of relative gene expression was performed by quantitative real-time PCR (qRT-PCR). cDNA was generated as previously described ${ }^{34}$. The reaction was run in triplicates using SYBR green dye according to manufacturer instructions. Reaction mixture comprised $6 \mu$ l (SYBR green + Primer $(\mathrm{F}+\mathrm{R}))$ mix and $4 \mu \mathrm{l} \mathrm{cDNA}$ making $10 \mu \mathrm{l}$ reaction volume each. Mean efficiencies were calculated by LinReg ${ }^{35}$. Relative expression data were calculated by qBase + (Biogazelle, Zwijnaarde, Belgium), with the normalization factors obtained from geNorm (geNorm $\mathrm{M}<0.5)^{36}$. Reference genes: glyceraldehyde 3-phosphate dehydrogenase (GAPDH_3), beta-2 microglobulin (B2m_2), ubiquitin C (UBC_1) and ribosomal protein lateral stack subunit PO (Rplpo). Selected target genes were tryptophan hydroxylase 2 (Tph2), 5-HT receptor 1 a (Htrla), 5-HT receptor $2 a$ (Htr2a), monoamine oxidase A (Maoa), arginine vasopressin receptor 1 a (Avpr1a).

Data analysis. Data obtained from this study were analyzed and displayed using GraphPad Prism version 6.07 for Windows (GraphPad Software, La Jolla California USA, www.graphpad.com). The total numbers of 5-HT ir cells counted in the anterior raphe of Tph2 icKO were compared with that of Tph2 CON mice using Kruskal-Wallis statistic $(H)$, while Dunn's multiple comparison test was used to compare means between the groups of mice.

Behavioral outcomes on baseline anxiety- and depression-like behavior were analyzed by one-way ANOVA. The course of 5-HT depletion from week 2, 4 and 6 were analyzed by two-way ANOVA as well as MS and gene expression data, with Tukey's multiple comparison post hoc test used to compare means. Students t-test was used for comparisons between Tph $2^{\Delta+/+}$ and Tph $2^{f l f l}$ mice (Figs. S1 and S2). An $\alpha<0.05$ was set as level of significance.

\section{Results}

Efficiency of induced Tph2 inactivation. The half-life of Tph2 is approximately 2.5 days $^{37}$. Thus, we first evaluated the time required after induced Tph2 recombination to reduce the amount of Tph2 synthesis to a level similar to constitutive Tph $2 \mathrm{KO}$ mice by immunohistochemistry (Fig. 1a). Four weeks after TAM treatment, effective recombination of Tph 2 was indicated by a significant drop of 5-HT ir cells in the DRN (Fig. 1b) of Tph 2 icKO compared with Tph $2 \mathrm{CON}$ mice $\left[\left(H_{2}\right)=7.731 ; p=0.0066\right.$; Fig. 1b, right panel $]$. The number of 5 -HT ir cells in the raphe region of Tph $2^{\Delta f l-}(p=0.0107)$ and $T p h 2^{\Delta f l f l}(p=0.0789)$ mice was reduced by $97.6 \%$ and $95.0 \%$ respectively compared to $T p h 2^{\Delta+/+}$ mice. After six weeks following TAM injection, only a few scat-

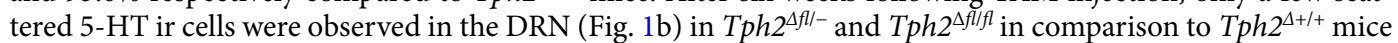
$\left(H_{2}\right)=16.43 ; p=0.0003$; Fig. 1b, right panel). Tph $2^{\Delta f l f l}(p=0.0006)$ and $T p h 2^{\Delta f l /-}(p=0.0023)$ showed a $93.7 \%$ and 92.2\% reduction of 5-HT ir cells compared to Tph $2^{\Delta+/+}$ mice. Similar to the DRN, the number of 5-HT ir cells in the MRN was decreased in Tph2 icKO after four weeks $\left(\left(H_{2}\right)=16.65 ; p=0.0002\right)$ and six weeks after treatment $\left(\left(H_{2}\right)=7.758 ; p=0.0062\right)$. Compared to $T p h 2^{\Delta+/+}$ mice, a significantly reduced number of 5 -HT ir cells in $T p h 2^{\Delta f l f l}(p=0.0053)$ and $T p h 2^{\Delta f l-}(p=0.0003)$ was detected by week four. Similar observations were recorded by week six in $T p h 2^{\Delta f l f l}(p=0.0783)$ and $T p h 2^{\Delta f l-}(p=0.016)$, which accounted for $92.7 \%$ and $82.1 \%$ reduction, respectively (Fig. 1c). Of note the number of 5-HT ir cells in DRN and MNR of Tph $2^{\Delta+/+}$ mice did not differ to vehicle treated Tph $2^{f l l f l}$ mice (Fig. S1).

Neurochemistry. In order to relate the absence of 5-HT ir cells to concentrations of monoamines in the raphe and target brain regions, we measured the concentrations of 5-HT and its metabolite, 5-hydroxyindolacetic acid (5-HIAA), as well as norepinephrine (NE) and dopamine (DA) in the raphe, hippocampus and amygdala at all three time points after TAM induction. Two-way ANOVA revealed a tendency towards significance in the raphe for genotype $\times$ time interaction $\left(\mathrm{F}_{(4,40)}=2.299 ; p=0.0756\right)$. Indeed, from week 2 to 6 Tph $2^{\Delta+/+}$ presented increased 5-HT concentrations $(p=0.0032)$ in the brainstem at a comparable level to wildtype $\left(T p h 2^{+/+}\right)$

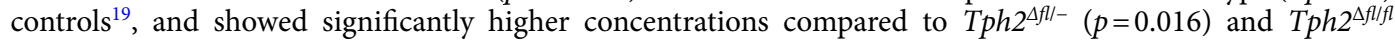
$(p=0.0783)$ mice. The concentration of $5-\mathrm{HT}$ in $T p h 2^{\Delta f l-}$ and $T p h 2^{\Delta f l l f l}$ mice was relatively stable at all time points, remaining at low concentrations $(67.0 \pm 13.6 \mathrm{ng} / \mathrm{ml})$, similar to those reported in constitutive Tph2 $2^{-/-}$ mice $^{19}$ (Fig. 2a, left panel). Moreover, the concentrations of the 5-HT metabolite 5-HIAA remained consistently low in both genotypes of Tph2 icKO mice at all time points examined. However, two-way ANOVA revealed a significant genotype $\times$ time interaction $\left(\mathrm{F}_{(4,40)}=8.157 ; p<0.0001\right.$; Fig. 2b, left panel), showing higher 5-HIAA in $T p h 2^{\Delta+l+}$ compared to $T p h 2^{\Delta f l f l}$ and $T p h 2^{\Delta f l /-}$ (both $p<0.0001$ ) only two weeks after injections.

In the hippocampus a significant genotype $\times$ time interaction was detected $\left(\mathrm{F}_{(4,40)}=6.493 ; p=0.0004\right.$; Fig. 2a, middle panel). Similar to the raphe, a rise in 5-HT concentrations in Tph $2^{\Delta+l+}$ mice from week 2 to 6 was

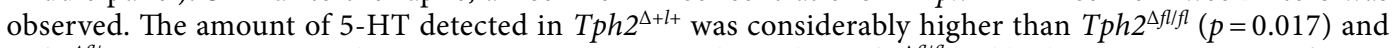
$T p h 2^{\Delta f l l-}(p=0.0013)$ in week 6. However, in contrast to the raphe, Tph $2^{\Delta f l f l}$ had higher concentrations of 5-HT at week 2, which declined until week 6, whereas in $T p h 2^{\Delta f l-}$ mice low 5-HT concentrations were detected at all time points. This provides evidence that recombination of two functional Tph2 alleles requires more time to effect changes in 5-HT concentrations in hippocampal projections. Furthermore, hippocampal 5-HIAA concentrations revealed a significant genotype $\times$ time interaction $\left(\mathrm{F}_{(4,40)}=4.776 ; p=0.003\right.$; Fig. $2 \mathrm{~b}$, middle panel). In week 
Tph2 fI/fI::TphCreERT2

Tph2 $2^{\text {fl/-::TphCreERT2 }}$

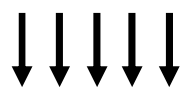

IHC

IHC

Tph2+/+::TphCreERT2

Week 10

HPLC

HPLC

HPLC

.

12

14

16

b
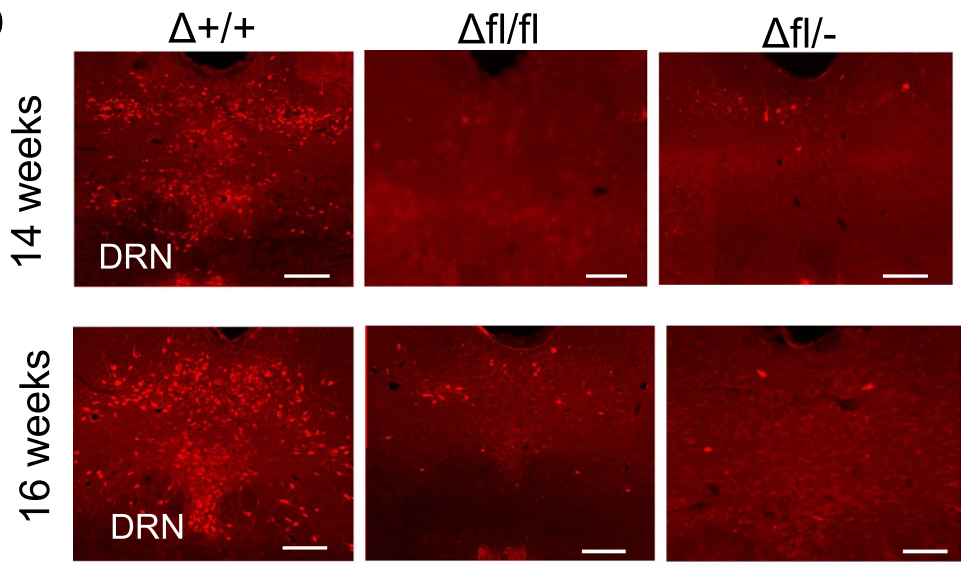

C
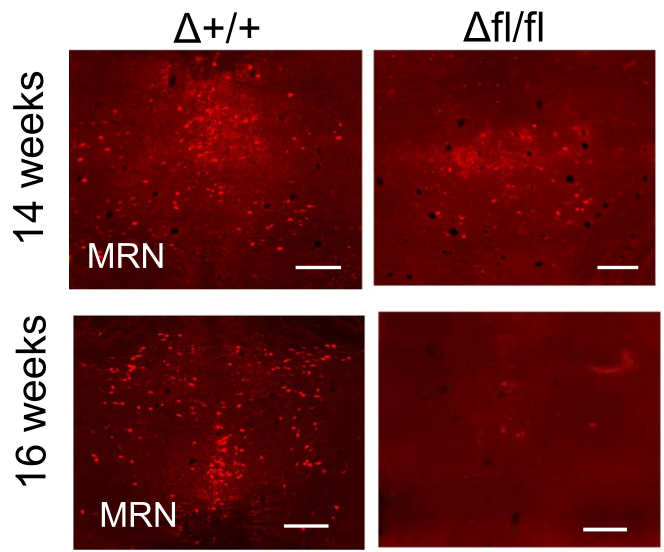
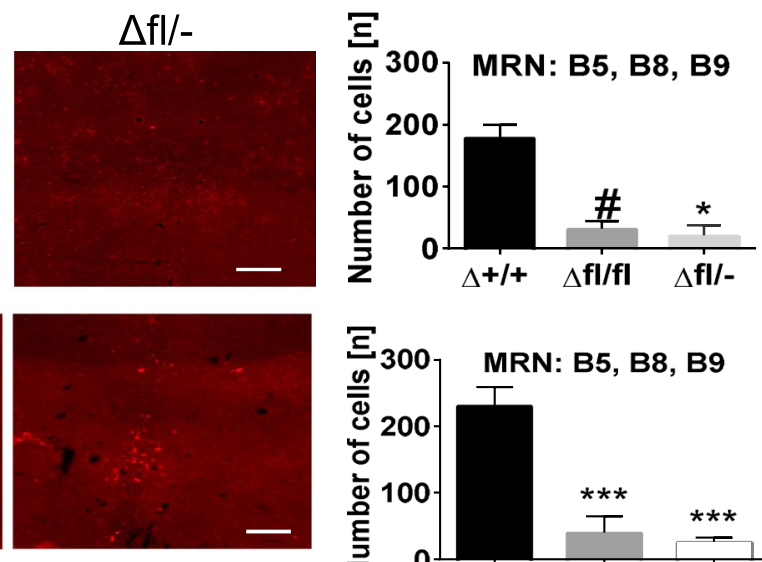
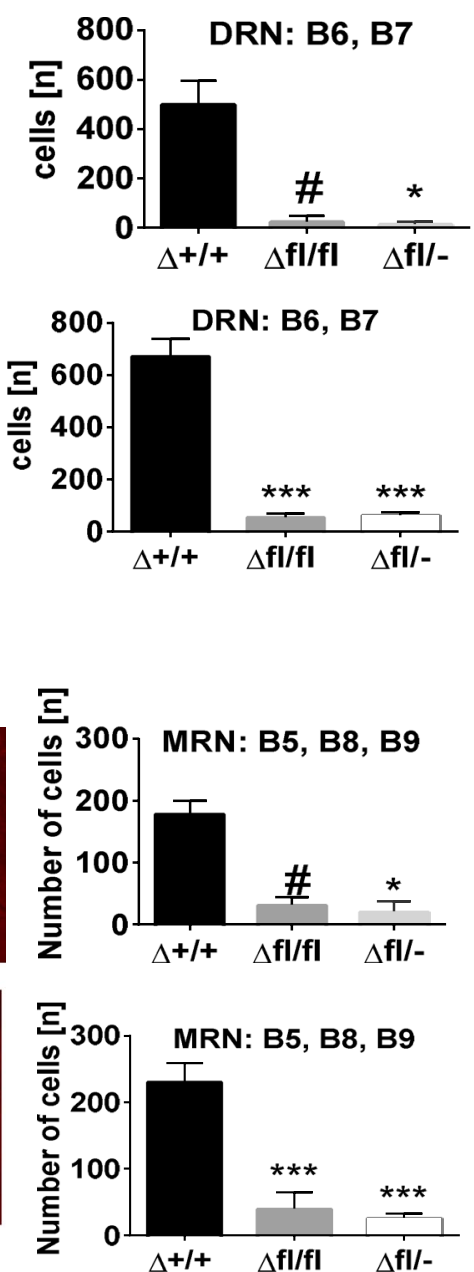

Figure 1. Tamoxifen (TAM)-induced Cre/fl-mediated inactivation of the tryptophan hydroxylase-2 (Tph2) gene during adulthood in raphe 5-HT neurons of $\mathrm{Tg}^{\mathrm{Tph} 2 \text { creERT2 }} / \mathrm{Tph} 2^{+/+}(\Delta+/+), \mathrm{Tg}^{\mathrm{TPh} 2 \mathrm{creERT2}} / \mathrm{Tph}^{\mathrm{f} / \mathrm{fl}}(\Delta \mathrm{fl} / \mathrm{fl})$ and $\mathrm{Tg}^{\mathrm{TPh} 2 \mathrm{creERT}} / \mathrm{Tph} 2^{\mathrm{H} / /}(\Delta \mathrm{fl} /-)$ mice. (a) Timeline for gene targeting, immunohistochemistry (IHC) and HPLC; (b) IHC and quantification of 5-HT positive cells in the dorsal raphe nucleus (DRN) B6 and B7 at week 14 (upper panel) and week 16 (lower panel) after treatment; (c) IHC and quantification of 5-HT positive cells in MRN at week 14 (upper panel) and week 16 (lower panel) after treatment. Number of 5-HT positive cells counted represented as mean \pm SEM in week $14(n=4 /$ group $)$ and week $16(n=6-9)$. Data are shown as mean \pm SEM. $\# 0.05<p<0.1,{ }^{*} p<0.05$ and ${ }^{* *} p<0.001$.

2, Tph $2^{\Delta+l+}$ displayed significantly higher concentrations of 5-HIAA than Tph $2^{\Delta f l f l}$ and Tph $2^{\Delta f l l-}($ both $p<0.0001)$ like in the brainstem, which was also detected in week $4\left[T p h 2^{\Delta f l / f l}(p=0.0767)\right.$; Tph $\left.2^{\Delta f l-}(p=0.0258)\right]$ and week $6\left[T p h 2^{\Delta f l f l}(p=0.0683) ; T p h 2^{\Delta f l /-}(p=0.0285)\right]$ also less pronounced.

In the amygdala a significant genotype $\times$ time interaction effect was observed $\left(\mathrm{F}_{(4,40)}=9.316 ; p<0.0001 ;\right.$ Fig. $2 \mathrm{a}$, right panel). Similar to the other brain regions, 5 -HT concentrations in $T p h 2^{\Delta+/+}$ was significantly lower compared to $T p h 2^{\Delta f l f l}(p=0.0023)$ and $T p h 2^{\Delta f l l-}(p=0.0214)$ at week two after induction and increased towards week 6 resulting in higher concentrations of 5-HT than Tph $2^{\Delta f l f l}(p=0.0004)$ and Tph $2^{\Delta f l /-}(p=0.0044)$. However, no 
Raphe

a
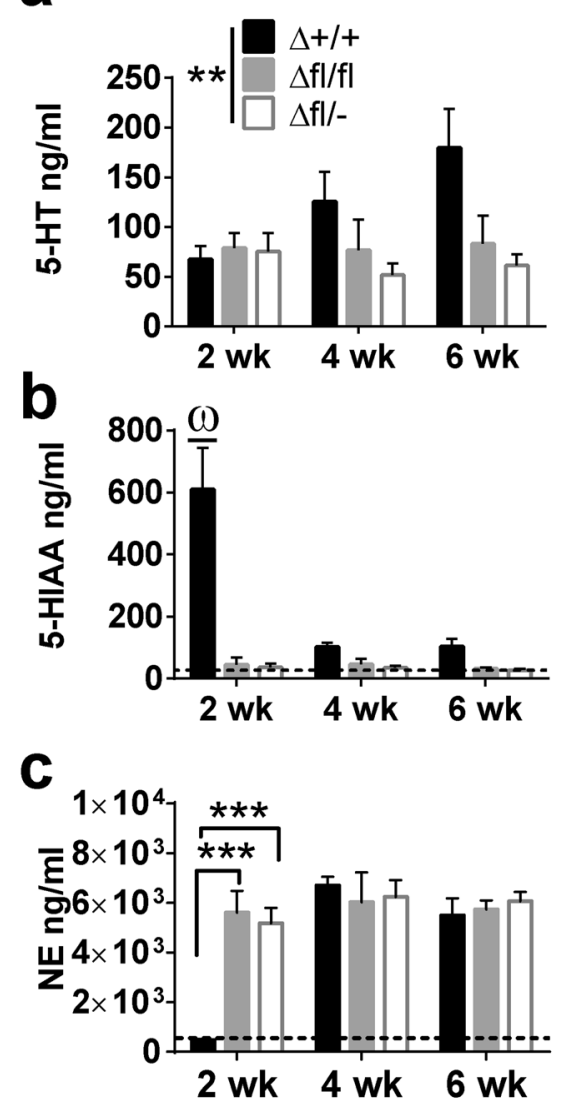

d

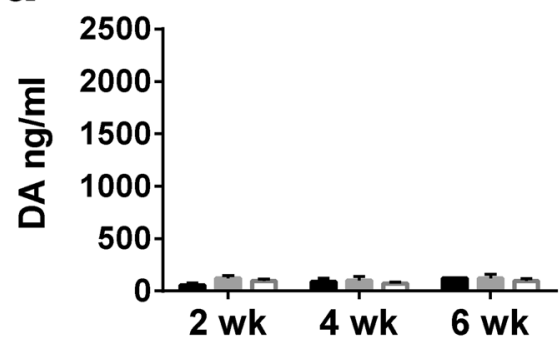

Hippocampus
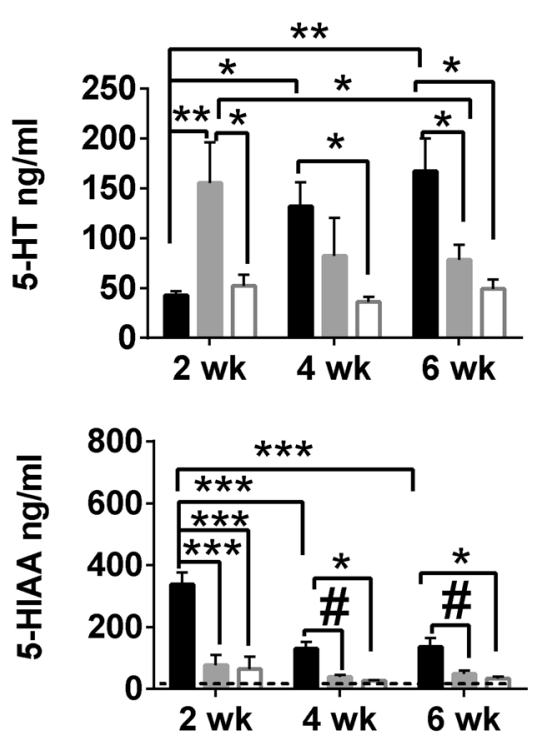
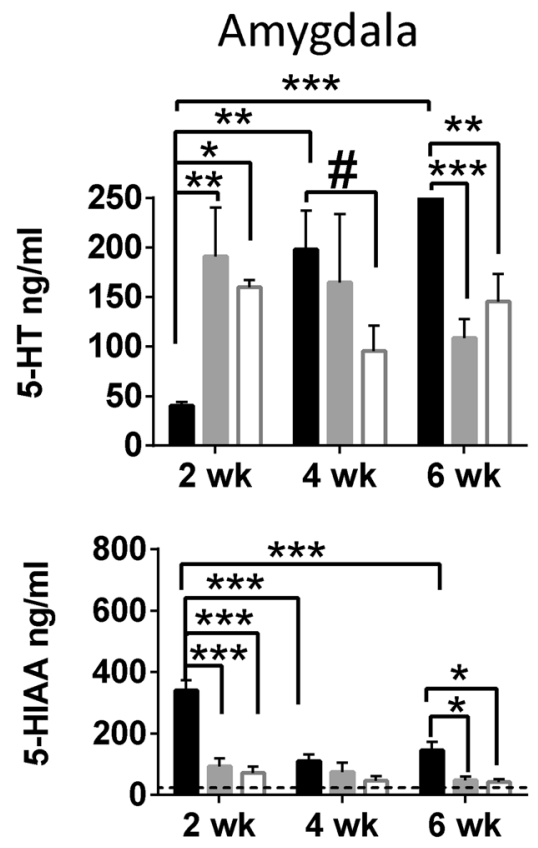
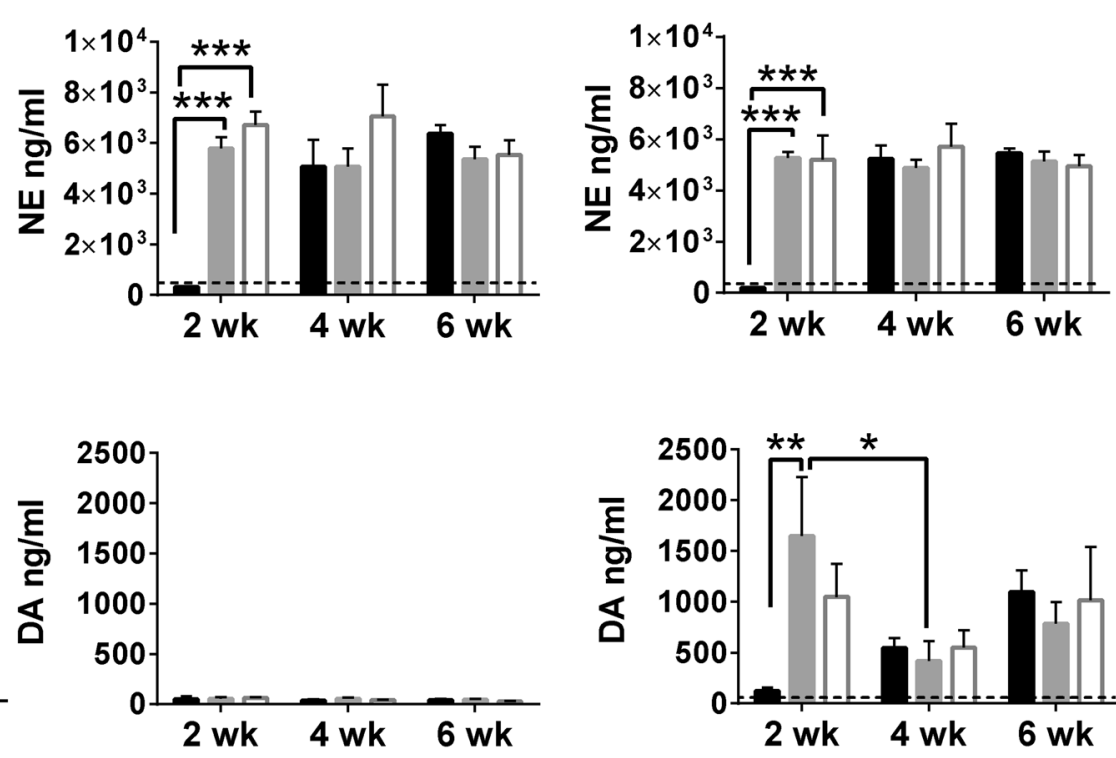

Figure 2. Concentrations of monoamines in brain of $T p h 2$ induced conditional knockout mice (Tph2 $2^{+/}$, $\left.T p h 2^{f l f l}, T p h 2^{f l-}\right)$. HPLC analysis of 5-HT in raphe, hippocampus and amygdala at week (wk) 2, 4 and 6 after induction; (a) 5-HT, (b) 5-HIAA, (c) NE, (d) DA in selected brain regions. Data are shown as mean \pm SEM. ${ }^{\#} 0.05<p<0.1,{ }^{* *} p<0.01,{ }^{* *} p<0.001$ and ${ }^{\omega} p<0.001$ compared to all groups.

significant changes were detected over time in Tph2 icKO mice, the concentration of 5-HT remained constantly high. Yet, the concentrations of 5-HIAA documented in the raphe, amygdala and hippocampus showed a sig-

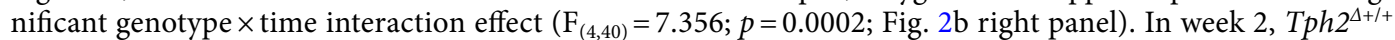

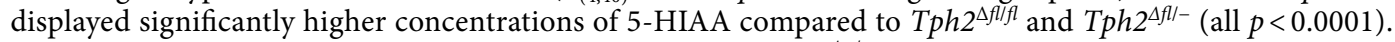
Whereas in week 4 , no significant differences were observed, $T p h 2^{\Delta+/+}$ showed higher concentrations of 5-HIAA than $T p h 2^{\Delta f l f l}(p=0.0184)$ and $T p h 2^{\Delta f l l-}(p=0.0114)$ in week 6 .

For NE two-way ANOVA revealed significant genotype $\times$ time interaction effects in the raphe $\left(\mathrm{F}_{(4,40)}=6.327\right.$; $p<0.0001$; Fig. 2c, left panel), hippocampus $\left(\mathrm{F}_{(4,40)}=9.862 ; p<0.0001\right.$; Fig. $2 \mathrm{c}$ middle panel $)$ and amygdala $\left(\mathrm{F}_{(4,40)}=62.804 ; p<0.0001\right.$; Fig. $2 \mathrm{c}$, right panel). Post-hoc analyses revealed that in all brain regions $T p h 2^{4+++}$ had

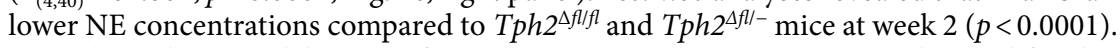

Only in the amygdala a significant genotype $\times$ time interaction was detected for the concentrations of DA $\left(\mathrm{F}_{(4,40)}=2.822 ; p=0.038\right.$; Fig. $2 \mathrm{~d}$, right panel). Post-hoc testing showed lower DA in Tph2 $2^{\Delta+/+}$ compared with $T p h 2^{\Delta f l l f l}(p=0.0024)$ and Tph $2^{\Delta f l /-}(p=0.0837)$ at week 2 . At week 4 DA concentrations in Tph $2^{\Delta f l / f l}$ dropped significantly compared to week $2(p=0.0385)$. At week 6 , no differences between genotypes were detected. Increased DA concentrations in $T p h 2^{\Delta+/+}$ at week 6 approached significance compared to week $2(p=0.065)$, indicating a 
a

Tamoxifen

(2x daily)

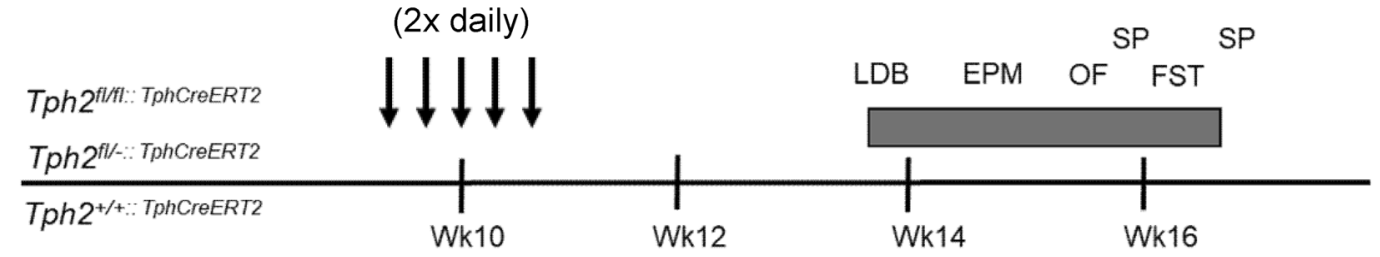

b

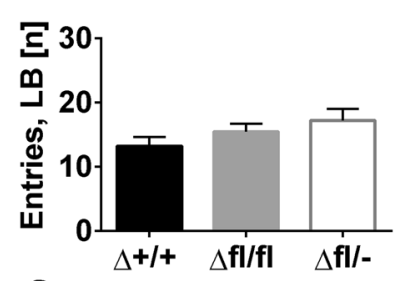

$f$
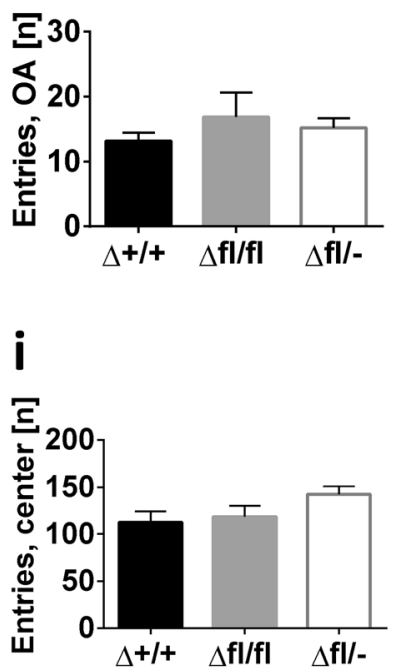

m

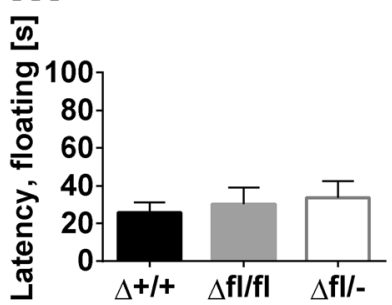

C

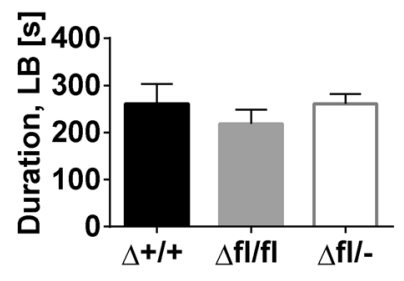

g

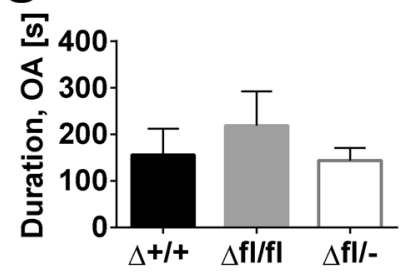

j

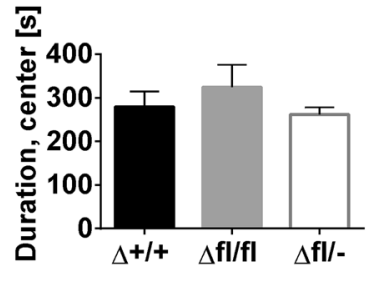

n

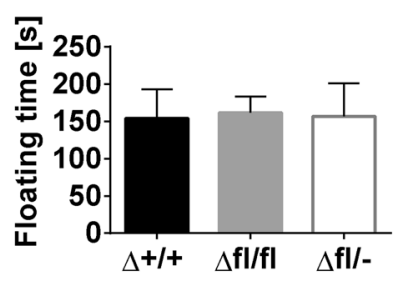

d
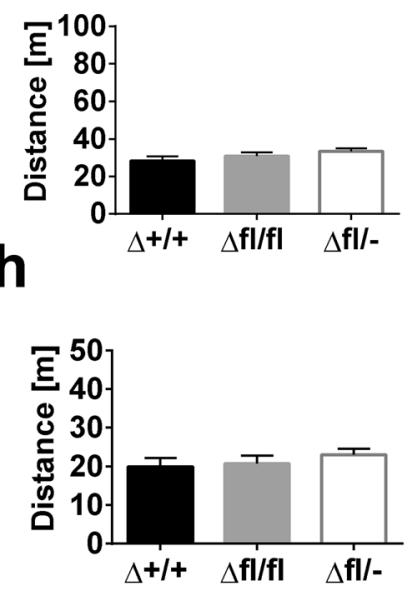

k

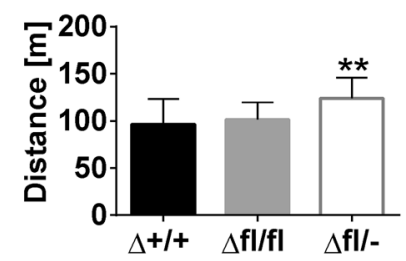

0

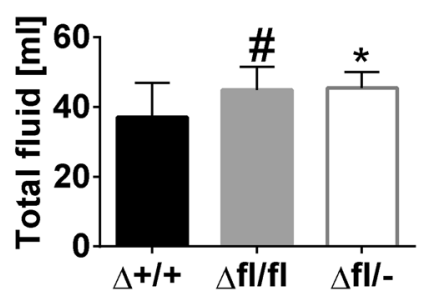

e

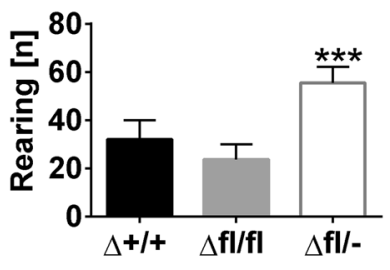

Figure 3. Lack of effects on anxiety- and depression-like but increased exploratory behavior in Tph2 icKO mice based on hemizygous genetic predisposition (a) Timelines for behaviour testing; (b)-(e) LDB: light box visits, time in light box, total distance and vertical rearings; (f)-(h) EPM: open arms visits, time in open arms and total distance; (i)-(l) OFT: center visits, time in center, total distance and jumping behavior; (m),(n) FST: latency to float and floating duration; (o),(p) SPT: total fluid consumed and sucrose preference. Data are shown as mean \pm SEM. $\# 0.05<p<0.1,{ }^{* *} p<0.01$ and ${ }^{* *} p<0.001$.

balancing effect in Tph $2^{\Delta+/+}$ over time. In the raphe (Fig. 2d, left panel) and hippocampus (Fig. 2d, middle panel) DA concentrations remained constant beyond all groups.

Locomotor hyperactivity but unaltered anxiety- and depression-like behavior in Tph2 icKO mice. After demonstrating the time course of 5-HT reduction after Tph2 icKO induction, we investigated anxiety and depressive-like behavior $4-6$ weeks after the injections (Fig. 3a). In the OF test, Tph $2^{\Delta+/+}, T p h 2^{\Delta f l /-}$ and $T p h 2^{\Delta f l / f}$ mice put up similar performances in the frequency of visits to the aversive center $\left(\mathrm{F}_{(2,39)}=2.431\right.$, 


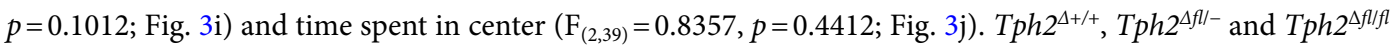
mice differed significantly in the total distance traveled (one-way ANOVA, $\mathrm{F}_{(2,39)}=6.224, p=0.0045$; Fig. 3k). Indeed, $T p h 2^{\Delta f l l-}$ traveled longer distances than $T p h 2^{\Delta+l+}$ and $T p h 2^{\Delta f l f l}(p=0.004)$. Furthermore, a tendency in favor of $T p h 2^{\Delta f l /-}$ was seen in jumping activity $\left(\mathrm{F}_{(2,39)}=2.944, p=0.0644\right.$; Fig. 31). In the LDT, Tph $2^{\Delta f l /-}$ and $T p h 2^{\Delta f l f l}$ mice did not differ from $T p h 2^{\Delta+/+}$ mice in all behavioral measures including entries and time spent in the lit compartment as well as total distance traveled (Fig. 3b-d). However, vertical rearing activities varied between groups $\left(\mathrm{F}_{(2,41)}=5.865, p=0.0058\right)$. Here Tph $2^{\Delta+/+}$ and $T p h 2^{\Delta f l /-}$ mice differed significantly $(p=0.0379$;

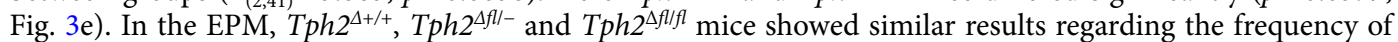
visits to the open arms $\left(\mathrm{F}_{(2,24)}=0.7034, p=0.5048\right.$; Fig. 3f $)$, time spent on open arms $\left(\mathrm{F}_{(2,24)}=0.5964, p=0.5587\right.$; Fig. $3 g)$ and total distance traveled $\left(\mathrm{F}_{(2,24)}=0.7257, p=0.4943\right.$; Fig. $\left.3 \mathrm{~h}\right)$.

Behavioral despair and anhedonia were tested in the FST and sucrose preference test. Tph $2^{\Delta+/+}, T p h 2^{\Delta f l /-}$ and $T p h 2^{\Delta f l f l}$ mice did not show any significant variation in latency to floating $\left(\mathrm{F}_{(2,24)}=0.2681, p=0.7671 ;\right.$ Fig. $\left.3 \mathrm{~m}\right)$

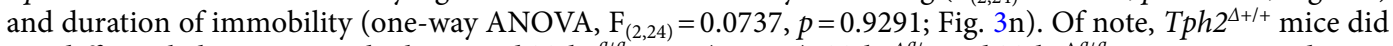
not differ in behaviour to vehicle treated Tph $2^{f l / f l}$ mice (Fig. S2). Tph $2^{\Delta f l l-}$ and Tph $2^{\Delta f l f l}$ mice consumed more fluid than $T p h 2^{\Delta+/+}$ mice $\left(\mathrm{F}_{(2,22)}=3.585, p=0.0449\right.$; Fig. 3o) with $T p h 2^{\Delta+/+}$ consuming significantly less fluid that $T p h 2^{\Delta f l-}(p=0.0384)$ and a tendency in comparison with $T p h 2^{\Delta f l f l}$ mice $(p=0.0992)$. In the SPT, differences in preference for sucrose were detected $\left(\mathrm{F}_{(2,22)}=5.972, p=0.0085\right.$; Fig. $\left.3 p\right)$ such that Tph $2^{\Delta f l f l}(p=0.0301)$ and $T p h 2^{\Delta f l-}(p=0.0076)$ preferred sucrose more than $T p h 2^{\Delta+/+}$.

Finally, we assessed whether reduced adult brain 5-HT synthesis affects body weight, food and water consumption in mice. There was no difference in body weight $\left(\mathrm{F}_{(2,61)}=0.3954, p=0.6751\right.$; Fig. 3c). However, experimental groups showed a statistical tendency towards quantity of water consumed $\left(\mathrm{F}_{(2,61)}=3.059, p=0.0542\right.$; Fig. S3b), with $T p h 2^{\Delta f l-}$ drinking more water. This is in line with $T p h 2^{\Delta f l l-}$ consuming a significant higher quantity of food $\left(\mathrm{F}_{(2,61)}=18.98, p<0.0001\right.$; Fig. S3a) than Tph $2^{\Delta+/+}(p<0.0001)$.

Anxiety- and depression-like behavior in MS-exposed mice. Several studies suggested that the functionality of 5-HT in adulthood may be primed by early-life adversity to render an individual susceptible to emotion related disorders ${ }^{38-40}$. Therefore, $\mathrm{Tg}^{\mathrm{Tph} 2 \text { creERT2}} / \mathrm{Tph}^{f l l f l}$ mice, were subjected to MS stress from P2-P16, injected with TAM in adulthood and tested for anxiety- and depression-like behavior (Fig. 4a).

In the $\mathrm{OF}$ test, no MS $\times$ treatment interaction in the number of visits to the center $\left(\mathrm{F}_{(1,32)}=2.275 ; p=0.1413\right.$; Fig. $4 \mathrm{~h})$ was detected. Considering the total time spent in the center, a significant MS $\times$ treatment interaction effect $\left(\mathrm{F}_{(1,32)}=6.562 ; p=0.015\right.$; Fig. $\left.4 \mathrm{i}\right)$ was observed. In the Non-MS group, $T p h 2^{\Delta f l f l}$ mice showed a tendency towards less time in the center $(p=0.077)$ compared with Tph2 CON. Inter-group comparison revealed that NonMS Tph $2^{\Delta f l f l}$ mice were more anxious than MS-exposed Tph $2^{\Delta f l f l}$ mice $(p=0.035)$. Furthermore, MS exposure potentially increased total distance travelled in the aversive center $\left(\mathrm{F}_{(1,32)}=6.562 ; p=0.09 ;\right.$ Fig. $\left.4 \mathrm{j}\right)$.

In the LDT, mice were assessed based on their activities in the open compartment of the box. Two-way ANOVA revealed no significant $\mathrm{MS} \times$ treatment interaction in measures of anxiety $\left(\mathrm{F}_{(1,32)}=0.9622 ; p=0.334\right.$, Fig. $4 \mathrm{~b}, \mathrm{c})$ and overall distance $\left(\mathrm{F}_{(1,32)}=0.6689 ; p=0.4195\right)$ travelled. However, Non-MS mice covered longer distance than MS exposed mice $\left(\mathrm{F}_{(1,32)}=12.49 ; p=0.0013\right)$ and $T p h 2^{\Delta f l f l}$ mice were more active compared to Tph2 CON mice $\left(\mathrm{F}_{(1,32)}=4.672\right.$; Fig. $\left.4 \mathrm{~d}\right)$.

In the $\mathrm{EPM}$, no significant MS $\times$ treatment interaction effect of was observed in visits to open arms $\left(\mathrm{F}_{(1,31)}=0.1966 ; p=0.6605\right.$; Fig. $\left.4 \mathrm{e}\right)$, total time spent on open arms $\left(\mathrm{F}_{(1,31)}=0.002 ; p=0.9644 ;\right.$ Fig. $\left.4 \mathrm{f}\right)$ and the overall distance covered $\left(\mathrm{F}_{(1,31)}=0.2576 ; p=0.6153\right)$. However, MS exposed mice $\left(\mathrm{F}_{(1,31)}=12.41 ; p=0.0014\right)$ covered less distance than Non-MS mice, while Tph $2^{\Delta f l f l}$ mice $\left(\mathrm{F}_{(1,31)}=5.392 ; p=0.027\right.$; Fig. $\left.4 \mathrm{~g}\right)$ covered longer distance than Tph2 CON mice, independent of MS exposure.

Evaluation of depression-like behavior in the PST in both MS- and Non MS-exposed mice revealed no behavioral deficits $\left(\mathrm{F}_{(1,31)}=0.3670 ; p=0.549\right.$; Fig. $\left.4 \mathrm{k}, \mathrm{l}\right)$.

Furthermore the SPT showed no significant effects on sucrose preference $\left(\mathrm{F}_{(1,31)}=0.3531 ; p=0.5566\right.$; Fig. $\left.4 \mathrm{~m}\right)$. With respect to total fluid consumed, a significant main effect of treatment occurred $\left(\mathrm{F}_{(1,31)}=20.9 ; p<0.0001\right.$; Fig. $4 \mathrm{n})$. Tph $2^{\Delta f l f l}$ mice consumed more fluid than Tph2 CON mice independent of aversive early-life stress experience. These outcomes indicate that reduction in adult brain 5-HT concentrations may not predispose to lack of pleasure that characterizes anhedonia but rather increases energy metabolism similar to constitutive Tph2 KOmice 20,71 .

Gene expression. The effect of MS-induced anxiety-related behavior on expression of genes, that are viewed as indicators of 5-HT system functionality in the raphe region, hippocampus and amygdala was also examined. Tph2 expression indicated no significant $\mathrm{MS} \times$ treatment interaction in the raphe region $\left(\mathrm{F}_{(1,31)}=0.1104\right.$; $p=0.7419)$. However, a significant main effect of treatment $\left(\mathrm{F}_{(1,31)}=30.05 ; p<0.0001\right)$ was apparent (Fig. 5a). Thus, expression of Tph2 was significantly reduced both in Non-MS and MS-exposed Tph2icKO mice which confirms the efficiency of conditional Tph2 inactivation.

The relative expression of Htrla in the raphe showed a significant main effect of treatment $\left(\mathrm{F}_{(1,31)}=4.345\right.$; $p=0.0456$; Fig. 5b) and a strong trend in the effect of $\mathrm{MS}\left(\mathrm{F}_{(1,31)}=3.597 ; p=0.0672\right.$; Fig. $\left.5 \mathrm{~d}\right)$. No change in hippocampus and amygdala was detected (Fig. S4c).

Relative expression of $\mathrm{Htr} 2 a$ in the raphe region indicated no significant MS $\times$ treatment interactions $\left(\mathrm{F}_{(1,31)}=0.3917 ; p=0.536\right)$ mice but a significant main effect of $\mathrm{MS}\left(\mathrm{F}_{(1,31)}=7.599 ; p=0.0097\right)$ and a trend towards treatment $\left(\mathrm{F}_{(1,31)}=3.328 ; p=0.0778\right.$; Fig. $\left.5 \mathrm{c}\right)$. No alterations in hippocampus and amygdala were detected (Fig. S4b).

Assessment of Maoa expression responsible for the degradation of 5-HT in the raphe revealed a general effect of TAM treatment with significantly lower expression in Tph 2 icKO than Tph 2 CON mice $\left(\mathrm{F}_{(1,31)}=13.39\right.$; 


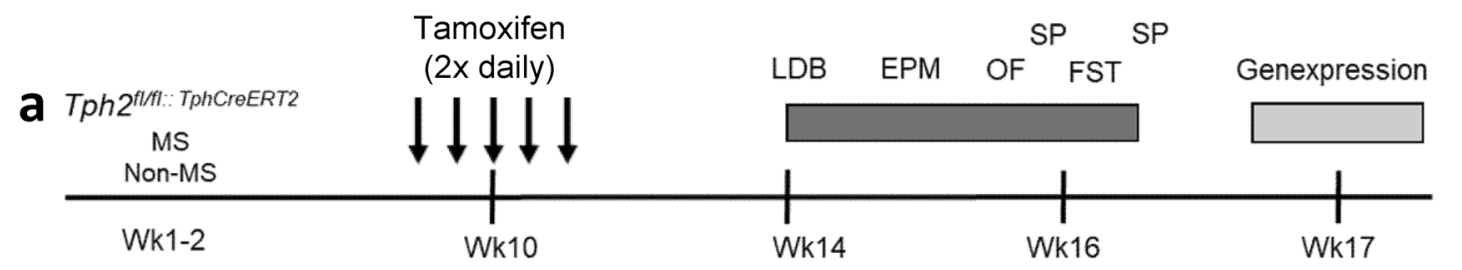

b
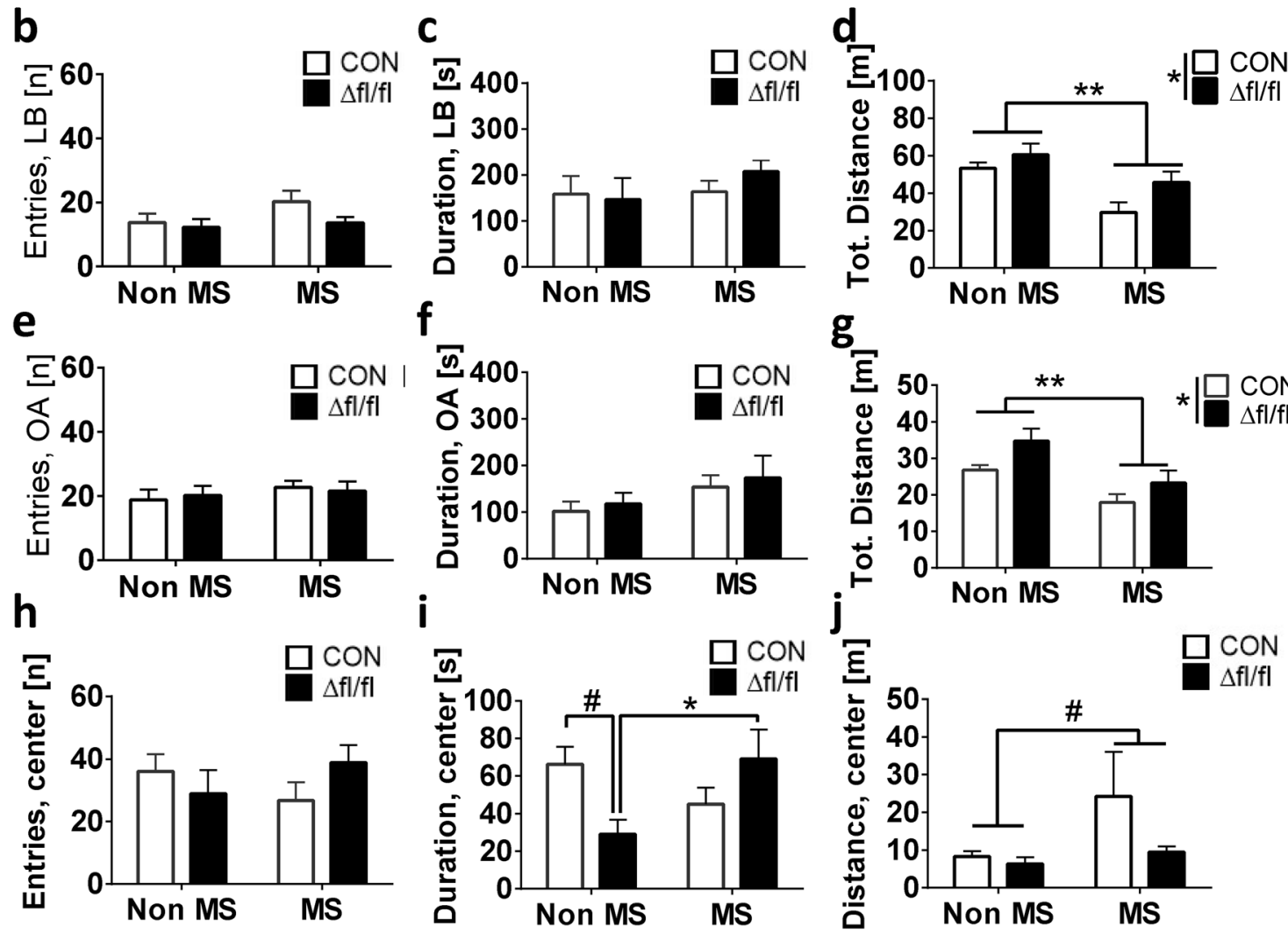

g
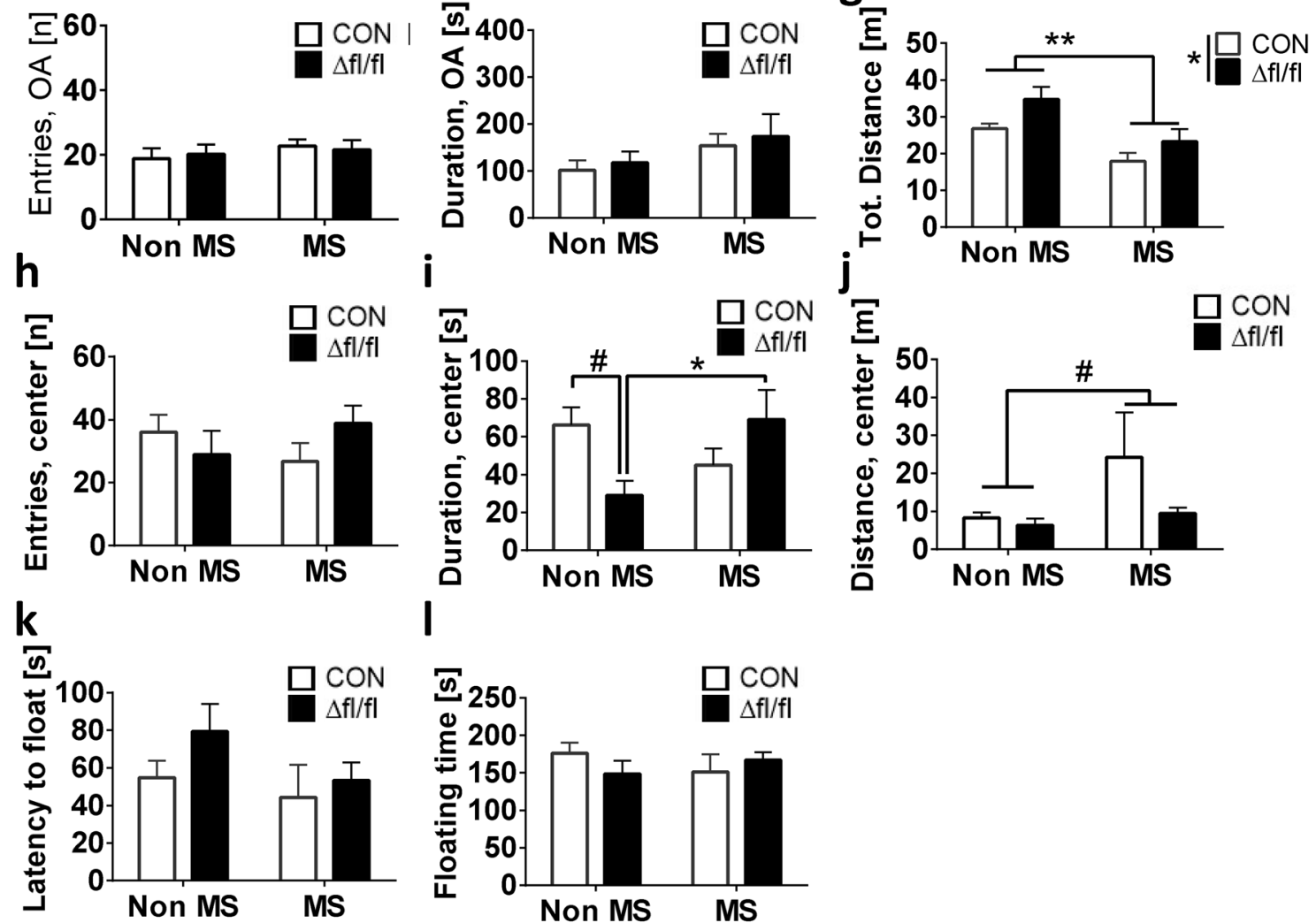

I
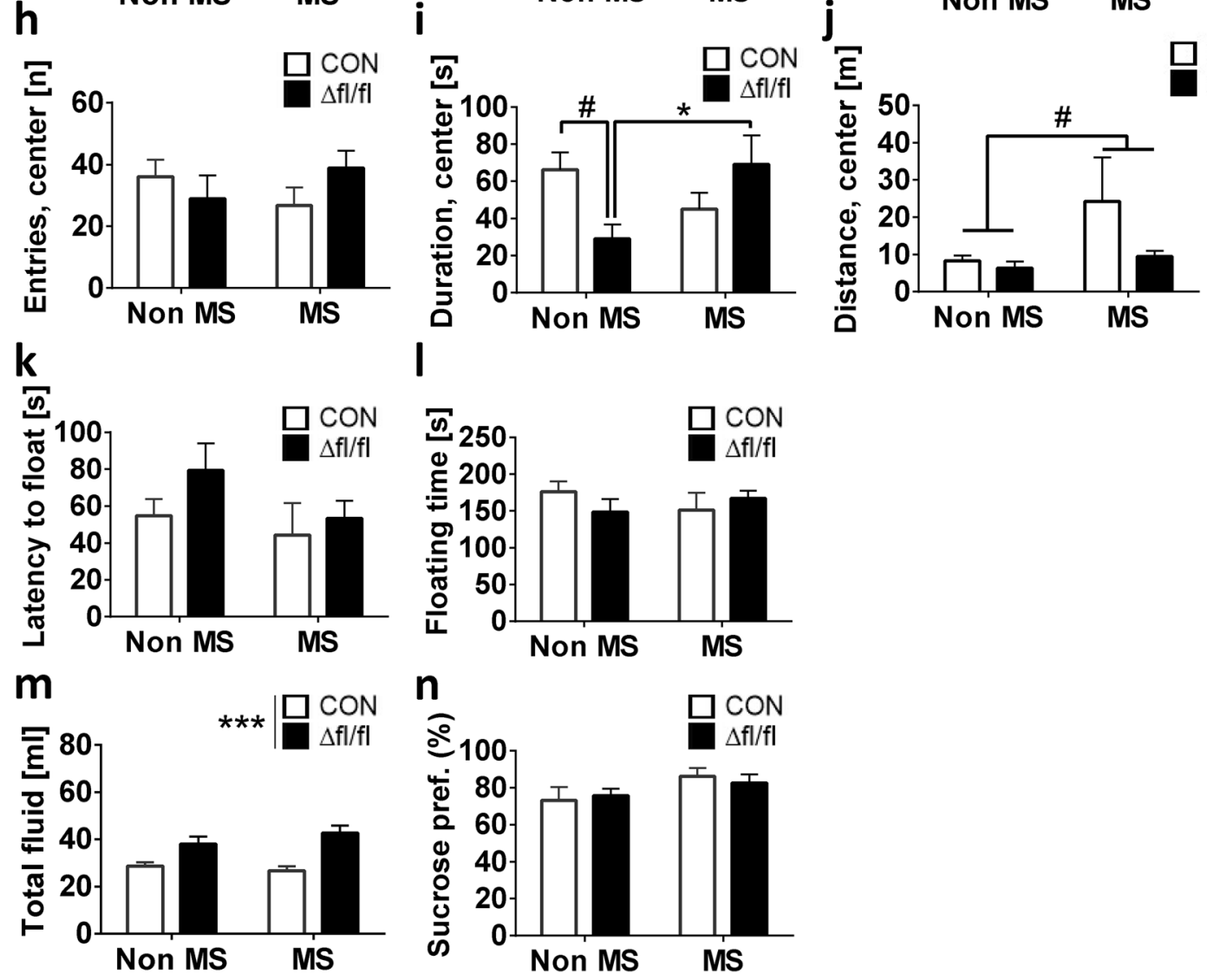

Figure 4. Anxiety-like, depression-like and exploratory behavior in MS-exposed Tph2 icKO mice with homozygous genetic predisposition $\left(T p h 2^{\Delta f l f l}\right)$. (a) Timelines for behavior testing; (b)-(d) LDB: light box visits, time in light box, total distance; (e)-(g) EPM: open arms visits, time in open arms and total distance; (h)-(j) OFT: center visits, time in center, total distance; (k),(l) FST: latency to float and floating duration; (m),(n) SPT: total fluid consumed and sucrose preference. Data are shown as mean \pm SEM. $\# 0.05<p<0.1,{ }^{* *} p<0.01$ and ${ }^{* * *} p<0.001$. 
a

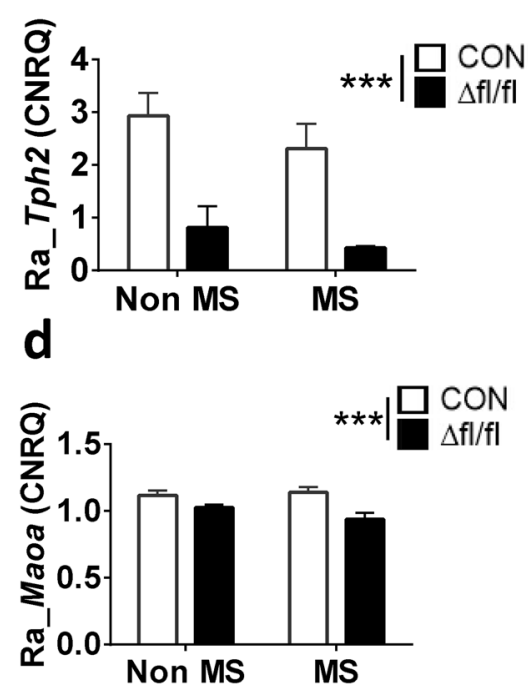

b

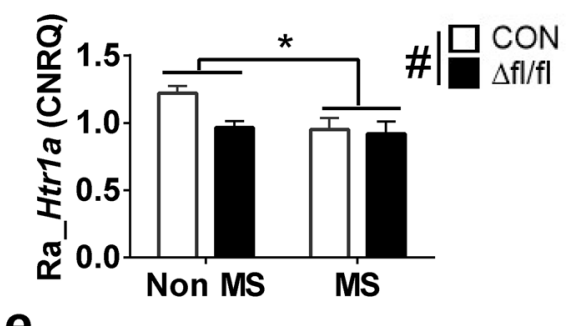

e

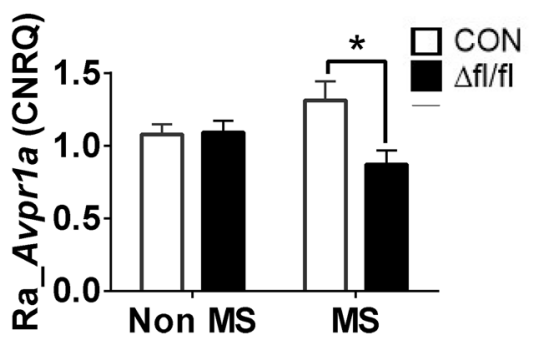

C

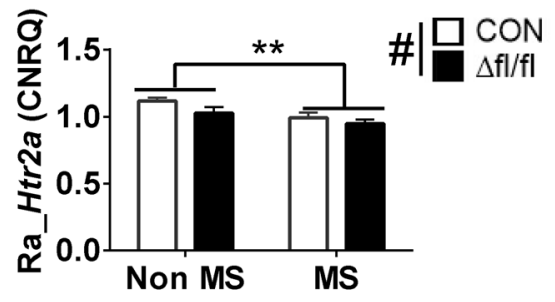

Figure 5. Expression of genes representing markers of 5-HT system function in the raphe region of MS-exposed Tph2 icKO mice with homozygous genetic predisposition. After behavioral testing maternally separated (MS) and normally reared non-MS Tph2 $2^{\mathrm{fl} / \mathrm{fl}: \mathrm{Tph} 2 \mathrm{CreERT2}}$ (fl/fl) mice, which were either injected at 10-12 weeks of age with TAM $(\Delta \mathrm{fl} / \mathrm{fl})$ or vehicle $(\mathrm{CON})$ were analysed for differential expression of $(\mathbf{a}) \mathrm{Tph} 2,(\mathbf{b})$ $H t r 1 a$, (c) Htr2a, (d) Maoa, (e) Avpr1. Data are shown as mean \pm SEM. $\# 0.05<p<0.1,{ }^{* *} p<0.01$ and ${ }^{* *} p<0.001$.

$p=0.0009$; Fig. 5d). By contrast, a main effect of MS occurred in target brain areas, such as hippocampus $\left(\mathrm{F}_{(1,31)}=4.399 ; p=0.0442\right.$; Fig. $\mathrm{S} 4 \mathrm{c}$, upper panel $)$ and amygdala $\left(\mathrm{F}_{(1,30)}=3.068 ; p=0.09\right.$; Fig. S4c, lower panel $)$. Avprla was reported to influence anxiety in humans and rodents ${ }^{34}$. In this study a significant MS $\times$ treatment interaction $\left(\mathrm{F}_{(1,31)}=5.44 ; p=0.0263\right.$; Fig. 5e) was observed in Avprla expression in raphe. Post-hoc analysis revealed Avpr1a expression in MS exposed Tph2 CON mice was higher than MS-exposed Tph2 icKO $(p=0.017)$. No differences were detected in the Non-MS cohort in both hippocampus and amygdala (Fig. S4d).

\section{Discussion}

The first part of this study capitalized on the TAM induced Cre-mediated inactivation of Tph2 to significantly reduce 5-HT synthesis in adult mouse brain. A transgenic Tph2-CreERT2 mouse line and the induction protocol described by (Weber et al. 2011) was used to induce a Tph2 knockout in adulthood. Although few 5-HT positive cells in the raphe region remained, which may point to ineffective nuclear translocation of Tph2-CreERT2 probably due to reduced expression of Tph2 in certain 5-HT immunoreactive neurons, we achieved similar recombination efficiencies as reported for other induced Tph $2 \mathrm{KO}$ mice using CMV-CreERT2 transgenics as Cre driver line $e^{41}$ or using AAV-Cre viral injection into the rostral raphe nuclei ${ }^{42}$. Furthermore, measurement of 5-HT concentrations four weeks after TAM induction in the raphe, hippocampus and amygdala revealed efficiently reduced 5-HT concentrations in Tph 2 icKO comparable to constitutive Tph $2^{-1-}$ null mutant mice ${ }^{19}$.

Efficient reduction of brain 5-HT and 5-HIAA within 4 weeks of TAM treatment has previously been reported $^{43}$, which indicates that the TAM-mediated induction approach requires a relatively long time period before a significant deficiency in brain 5-HT concentration is established. However, the HPLC results showing low concentrations of 5-HT in Tph $2^{\Delta+/+}$ combined with highly increased 5HIAA levels at week 2 differed to previous results of non-injected $T p h 2^{+/+}$mice in previous studies ${ }^{19}$. The increased 5-HT turnover in wildtype controls due to the stressful TAM injection protocol may represent a short time adaptive mechanism of the 5-HT system probably similar to restraint stress models ${ }^{44}$. Although, 5-HT concentrations in Tph $2^{\Delta f l-}$ and Tph $2^{\Delta f l / f l}$ mice did not differ in comparison with Tph $2^{\Delta+/+}$, the low 5-HIAA levels in both $T p h 2^{\Delta f l l-}$ and $T p h 2^{\Delta f l / f l}$ groups reflect reduced 5-HT turnover similar to Tph2 ${ }^{-/-}$null mutant mice in the DRN ${ }^{19}$. Nevertheless, it seems that it takes at least four weeks in Tph $2^{\Delta+l+}$ mice to recover from the injection stress indicated by increasing 5-HT concentrations in the DRN similar to that of $T p h 2^{+l+}$ wildtype mice without any injection ${ }^{19}$. Interestingly, in the hippocampus and amygdala this effect on Tph $2^{\Delta+/+}$ is detected as well but it seems that it takes longer after TAM injections that 5-HT levels become degraded as compared to the raphe nuclei, which might be due to differentially edited or spliced Tph 2 mRNA isoforms with enhanced stability itself and or its coding proteins $s^{45}$ within serotonergic projections targeting these regions. Still, remaining 5-HT in induced $T p h 2^{\Delta f l l-}$ and $T p h 2^{\Delta f l l f l}$ mice may arise from blood platelet 5-HT due to inefficient perfusion of the brain and/or from blood-borne 5-HTP derived from Tph1 enzymatic activity, which may cross the blood brain barrier and be converted into 5-HT by AADC ${ }^{16,19}$.

In line with the above explanation is an early increased concentration of NE in the brain coupled with expected reduction in 5-HT concentrations, which was probably caused by the injection procedure ${ }^{44}$. This shows that acute stress coupled with reduced 5-HT metabolism has an immediate influence on the NE and dopamine 
systems ${ }^{42}$. An effect, which normalized in the 4 th week after TAM injections. Thus, the observed alterations in brain DA and NE concentrations add on the results from other studies ${ }^{42,43}$.

Interestingly, unlike $T p h 2^{-1-}$ mice, which exhibit reduced anxiety-like behavior ${ }^{21,22,46}, T p h 2^{\Delta f l /-}$ and $T p h 2^{\Delta f l f l}$ mice showed no differences in anxiety- and depression-like behavior. However, locomotor hyperactivity or panic-like responses in aversive inescapable novel environment in $T p h 2^{-1-}$ mice $^{32}$ and locomotor hyperactivity as described for $T p h 2^{i c k o}$ mice ${ }^{42}$ were specifically observed in $T p h 2^{\Delta f l-}$, which resemble genetic heterozygous knockout mice with a $20-30 \%$ reduction in raphe 5-HT levels ${ }^{19}$. This is in line with reports of involvement of $\mathrm{DR}$ and MnR 5-HT in responses to future threat ${ }^{47,48}$. In contrast, Tph $2^{4 f l / f l}$ did not differ in any behavioral assessment compared to $T p h 2^{\Delta+/+}$ mice. Indeed, it points towards a two-hit effect ${ }^{49}$. Based upon a primed heterozygous genetic background during development, an induced or acquired 5-HT deficiency may provoke more pronounced panic-like flight responses in inescapable aversive conditions, while a development without changes in the 5-HT system like in $T p h 2^{\Delta f l l f l}$ is able to compensate further environmental or genetic impacts in adulthood despite the near complete ablation of 5-HT synthesis.

Interaction of early life MS stress and aberrant adult brain 5-HT on behavior. In order to further investigate this effect during early development, we used early life MS, which has been commonly used to study $\mathrm{G} \times \mathrm{E}$ interaction on anxiety and depression in mice ${ }^{50,51}$ and has been shown to impact anxiety-like behaviors in rodents via the 5-HT system ${ }^{52,53}$. Exposure of wildtype mice, on a mixed c57BL6/J-129S6/Sv background, to MS significantly decreased distance travelled and time spent in the center of the OFT, while MS had no effect in Tph2 KI mice ${ }^{54}$. Here, we could show that MS produced a similar effect in vehicle injected Tph $2^{f l f l}$ control mice and this effect was rescued by inducing a Tph2 deficiency. This shows that MS exposure and reduced brain 5-HT differentially influence anxiety-like behavior and may compensate each other.

Thus, this study complements numerous studies, which focused specifically on manipulation of Tph2 expression in adult mouse brain and its effect on emotion-related behavior ${ }^{42}$. Aberrant 5-HT neurotransmission in the adult brain either via pharmacological interventions $s^{55,56}$ or induced gene inactivation ${ }^{42,43}$ was unable to destabilize behavioral adaptive mechanisms that are established during early brain maturation.

Notably, neither MS nor induced adult 5-HT deficiency altered preferences for sucrose solution indicating no differences in hedonic-like behaviors. Furthermore, no alterations in depression-like behavior in the PST were observed in this study. One explanation may be that maternal care on reunion with pups increased and this may have dissolved the MS effect on depression-like behaviors. Thus, it may well be that the MS protocol used was not robust enough to impact depression-like behavior in the mice $\mathrm{e}^{57}$ and requires further studies including investigation of maternal behaviour. MS exposure neither affected hedonic behavior in rats ${ }^{58}$, nor did it impact anxiety- and depression-related behavior in C57BL/6 mice ${ }^{59}$. Even in TPH2 KI mice, which have reduced brain 5 -HT concentrations throughout life, MS exposure did not alter anxiety- and depressive-like behaviors ${ }^{60}$. By contrast, some studies have associated MS exposure with abnormal behavior and stress induced alteration in neurotransmitter concentration ${ }^{61,62}$. Noteworthy, most rodent studies, which found an association between MS with behavioral alterations, were largely done in rats ${ }^{62-64}$. Indeed, some C57BL/6 mouse strains appear to be resilient to neonatal MS stress ${ }^{57,59,65-70}$, which may explain the weak MS effects observed in this study.

However, Tph 2 icKO mice consumed more fluid than Tph2 CON mice, which points towards an acute metabolic effect of 5-HT deficiency in Tph2 $\mathrm{KO}$ mice ${ }^{71}$. The observed increase in food, water and percentage sucrose consumption by $T p h 2^{\Delta f l-}$ and $T p h 2^{\Delta f l f l}$ mice has also been reported in $T p h 2^{-l-}$ mice ${ }^{20,71}$, which reflects an increased energy need, rather than altered anhedonia as a symptom of depressive-like behavior. This supports the assertion that strong reductions in 5-HT metabolism in adulthood are implicated in the pathophysiology of eating disorders through various hormonal and receptor systems $\mathrm{s}^{72,73}$, independent of 5-HT functions during development.

Gene expression in raphe, hippocampus and amygdala. Early-life stress does not alter the expression of Tph 2 in mice ${ }^{60}$ and rats ${ }^{52}$. In contrast, an association between MS exposure and raphe region-specific reduction in Tph2 expression of C56BL/6 J mice has been reported ${ }^{74}$. Here, the relative expression of Tph2 in $T p h 2$ icKO was significantly lower than Tph2 CON mice in raphe, while MS exposure alone did not alter Tph2 expression.

We detected no differences in expression of Htr1a, Htr2a and Avpr1a in target regions of MS-naive mice. This confirms our earlier work, which also reporting no change in expression of Htrla and Htr2a genes in non-stressed $T p h 2$ conditional KO mice ${ }^{75}$. A slightly altered expression of Maoa in amygdala and hippocampus may point to specific compensatory mechanisms due to $\mathrm{MS}^{53}$. Furthermore, MS exposed mice showed altered expression of Htrla and Htr2a in the raphe independent of Tph2 icKO, which is in line with previous MS studies ${ }^{76,77}$. Alterations in 5-HT receptors in target regions of 5-HT neurons have previously been associated with altered anxiety and exploratory behavior ${ }^{78}$. Here, this may explain the dampening effect of MS on total locomotor activity in OF and EPM.

However, a Tph 2 icKO reduced expression of Maoa in the raphe region, pointing towards a direct effect of strong 5-HT depletion on MaoA dependent 5-HT turnover processes. Thus, effects mediated by adverse life experience and associated with altered Maoa expression ${ }^{34}$ may be prohibited in Tph 2 icKO mice through a dysfunctional 5-HT system in adulthood. Interestingly, Avprla expression was only affected in the raphe after the mice were maternally separated. We did not find altered Avprla expression in the hippocampus, which was correlated after late adverse life experiences with reduced anxiety-like behavior ${ }^{34}$. Nevertheless, Avprla is present in the dorsal raphe, the mesencephalic central gray and the caudal linear raphe ${ }^{79}$. Additionally, an Avprla knockout as well as pharmacological blockade of Avprla function in rodents reduced aggression and resulted in anxiolytic and anti-depressive-like effects ${ }^{80,81}$. Thus, the potential anxiolytic effect observed in MS 
Tph2 icKO mice may be directly attributable to altered Avprla expression. This highlights the interaction of arginine vasopressin-dependent signaling with the 5-HT system in the brainstem following MS as a potential therapeutic target for treating emotional dysregulation.

In conclusion. Our findings establish a "double-hit" experimental model to study the behavioral and neurobiological consequences of 5-HT deficiency in adulthood in interaction with early-life stress experience potentially affecting emotion regulation and the pathogenesis of depressive disorders.

Received: 24 May 2020; Accepted: 22 January 2021

Published online: 08 March 2021

\section{References}

1. Murphy, D. L. \& Lesch, K. P. Targeting the murine serotonin transporter: insights into human neurobiology. Nat. Rev. Neurosci. 9, 85-96 (2008).

2. Ottenhof, K. W., Sild, M., Levesque, M. L., Ruhe, H. G. \& Booij, L. TPH2 polymorphisms across the spectrum of psychiatric morbidity: A systematic review and meta-analysis. Neurosci. Biobehav. Rev. 92, 29-42 (2018).

3. Gonzalez-Castro, T. B., Juarez-Rojop, I., Lopez-Narvaez, M. L. \& Tovilla-Zarate, C. A. Association of TPH-1 and TPH-2 gene polymorphisms with suicidal behavior: A systematic review and meta-analysis. BMC Psychiatry 14, 196 (2014).

4. Walther, D. J. \& Bader, M. A unique central tryptophan hydroxylase isoform. Biochem. Pharmacol. 66, 1673-1680 (2003).

5. Cote, F. et al. Disruption of the nonneuronal tph1 gene demonstrates the importance of peripheral serotonin in cardiac function. Proc. Natl. Acad. Sci. USA 100, 13525-13530 (2003).

6. Bell, C., Abrams, J. \& Nutt, D. Tryptophan depletion and its implications for psychiatry. Br. J. Psychiatry 178, 399-405 (2001).

7. Sanchez, C. L. et al. Simplified dietary acute tryptophan depletion: effects of a novel amino acid mixture on the neurochemistry of C57BL/6J mice. Food Nutr. Res. 59, 66 (2015).

8. van Donkelaar, E. L. et al. Mechanism of acute tryptophan depletion: Is it only serotonin?. Mol. Psychiatry 16, 695-713 (2011).

9. Kaye, W. H. et al. Anxiolytic effects of acute tryptophan depletion in anorexia nervosa. Int. J. Eat. Disord. 33, 257-267 (2003).

10. Young, S. N. Methodology and interpretation of acute tryptophan depletion studies. Acta Psychiatry Scand. 129, 156 (2014).

11. Kaye, W. H. et al. Effects of acute tryptophan depletion on mood in bulimia nervosa. Biol. Psychiatry 47, 151-157 (2000).

12. Feenstra, M.G. \& van der Plasse, G. Tryptophan depletion and serotonin release-A critical reappraisal. 249-258 (2010).

13. Blokland, A., Lieben, C. \& Deutz, N. E. Anxiogenic and depressive-like effects, but no cognitive deficits, after repeated moderate tryptophan depletion in the rat. J. Psychopharmacol. 16, 39-49 (2002).

14. Liu, C. et al. Pet-1 is required across different stages of life to regulate serotonergic function. Nat. Neurosci. 13, 1190-1198 (2010).

15. Dai, J. X. et al. Enhanced contextual fear memory in central serotonin-deficient mice. Proc. Natl. Acad. Sci. USA 105, 11981-11986 (2008).

16. Alenina, N. et al. Growth retardation and altered autonomic control in mice lacking brain serotonin. Proc. Natl. Acad. Sci. USA 106, 10332-10337 (2009).

17. Erickson, J. T., Shafer, G., Rossetti, M. D., Wilson, C. G. \& Deneris, E. S. Arrest of 5HT neuron differentiation delays respiratory maturation and impairs neonatal homeostatic responses to environmental challenges. Respir. Physiol. Neurobiol. 159, 85-101 (2007).

18. Gutknecht, L., Kriegebaum, C., Waider, J., Schmitt, A. \& Lesch, K. P. Spatio-temporal expression of tryptophan hydroxylase isoforms in murine and human brain: Convergent data from Tph2 knockout mice. Eur. Neuropsychopharmacol. 19, 266-282 (2009).

19. Gutknecht, L. et al. Impacts of brain serotonin deficiency following Tph2 inactivation on development and raphe neuron serotonergic specification. PLoS ONE 7, e43157 (2012).

20. Angoa-Perez, M. et al. Mice genetically depleted of brain serotonin do not display a depression-like behavioral phenotype. ACS Chem. Neurosci. 5, 908-919 (2014).

21. Angoa-Perez, M. et al. Genetic depletion of brain $5 \mathrm{HT}$ reveals a common molecular pathway mediating compulsivity and impulsivity. J. Neurochem. 121, 974-984 (2012).

22. Mosienko, V. et al. Exaggerated aggression and decreased anxiety in mice deficient in brain serotonin. Transl. Psychiatry 2, 66 (2012).

23. Gaspar, P., Cases, O. \& Maroteaux, L. The developmental role of serotonin: News from mouse molecular genetics. Nat. Rev. Neurosci. 4, 1002-1012 (2003).

24. Riccio, O. et al. Excess of serotonin affects embryonic interneuron migration through activation of the serotonin receptor 6. Mol. Psychiatry 14, 280-290 (2009).

25. Waider, J. et al. GABA concentration and GABAergic neuron populations in limbic areas are differentially altered by brain serotonin deficiency in Tph2 knockout mice. Histochem. Cell Biol. 139, 267-281 (2013).

26. Gutknecht, L. et al. Deficiency of brain 5-HT synthesis but serotonergic neuron formation in Tph2 knockout mice. J. Neural Transm. 115, 1127-1132 (2008).

27. Weber, T. et al. Inducible gene manipulations in serotonergic neurons. Front. Mol. Neurosci. 2, 24 (2009).

28. Alonso, A. et al. Development of the serotonergic cells in murine raphe nuclei and their relations with rhombomeric domains. Brain Struct. Funct. 218, 1229-1277 (2013).

29. Deneris, E. S. Molecular genetics of mouse serotonin neurons across the lifespan. Neuroscience 197, 17-27 (2011).

30. Schindelin, J. et al. Fiji: An open-source platform for biological-image analysis. Nat. Methods 9, 676-682 (2012).

31. Franklin, K.B.J. \& Paxinos, G. The Mouse Brain in Stereotaxic Coordinates, xxii p. 186 p. of Plates (Academic Press, San Diego, 1997).

32. Waider, J. et al. Genetically driven brain serotonin deficiency facilitates panic-like escape behavior in mice. Transl. Psychiatry 7 , e1246 (2017).

33. Gutknecht, L. et al. Interaction of brain 5-HT synthesis deficiency, chronic stress and sex differentially impact emotional behavior in Tph2 knockout mice. Psychopharmacology 6, 58 (2015).

34. Bodden, C., van den Hove, D., Lesch, K. P. \& Sachser, N. Impact of varying social experiences during life history on behaviour, gene expression, and vasopressin receptor gene methylation in mice. Sci. Rep. 7, 8719 (2017).

35. Ruijter, J. M. et al. Amplification efficiency: linking baseline and bias in the analysis of quantitative PCR data. Nucleic Acids Res. 37, e45 (2009).

36. Vandesompele, J. et al. Accurate normalization of real-time quantitative RT-PCR data by geometric averaging of multiple internal control genes. Genome Biol 3, RESEARCH0034 (2002).

37. Meek, J. L. \& Neff, N. H. Tryptophan 5-hydroxylase: Approximation of half-life and rate of axonal transport. J. Neurochem. 19, 1519-1525 (1972).

38. Yohn, C. N., Gergues, M. M. \& Samuels, B. A. The role of 5-HT receptors in depression. Mo.l Brain 10, 28 (2017). 
39. Houwing, D. J., Buwalda, B., van der Zee, E. A., de Boer, S. F. \& Olivier, J. D. A. The serotonin transporter and early life stress: Translational perspectives. Front. Cell. Neurosci. 11, 587 (2017).

40. Underwood, M. D. et al. Serotonin receptors and suicide, major depression, alcohol use disorder and reported early life adversity. Transl. Psychiatry 8, 279 (2018).

41. Pelosi, B., Pratelli, M., Migliarini, S., Pacini, G. \& Pasqualetti, M. Generation of a Tph2 conditional knockout mouse line for timeand tissue-specific depletion of brain serotonin. PLoS ONE 10, e0136422 (2015).

42. Whitney, M. S. et al. Adult brain serotonin deficiency causes hyperactivity, circadian disruption, and elimination of siestas. J. Neurosci. 36, 9828-9842 (2016).

43. Song, N. N. et al. Reducing central serotonin in adulthood promotes hippocampal neurogenesis. Sci. Rep. 6, 89 (2016).

44. Neufeld-Cohen, A. et al. Chronic activation of corticotropin-releasing factor type 2 receptors reveals a key role for 5-HT1A receptor responsiveness in mediating behavioral and serotonergic responses to stressful challenge. Biol. Psychiatry 72, 437-447 (2012).

45. Grohmann, M. et al. Alternative splicing and extensive RNA editing of human TPH2 transcripts. PLoS ONE 5, e8956 (2010).

46. Mosienko, V. et al. Life without brain serotonin: Reevaluation of serotonin function with mice deficient in brain serotonin synthesis. Behav. Brain Res. 277, 78-88 (2015).

47. Baldwin, D. \& Rudge, S. The role of serotonin in depression and anxiety. Int. Clin. Psychopharmacol. 9(Suppl 4), 41-45 (1995).

48. Deakin, J. The role of serotonin in depression and anxiety. Eur. Psychiatry 13(Suppl 2), 57s-63s (1998).

49. Girirajan, S. \& Eichler, E. E. Phenotypic variability and genetic susceptibility to genomic disorders. Hum. Mol. Genet. 19, R176R187 (2010).

50. Fabricius, K., Wortwein, G. \& Pakkenberg, B. The impact of maternal separation on adult mouse behaviour and on the total neuron number in the mouse hippocampus. Brain Struct. Funct. 212, 403-416 (2008).

51. George, E. D., Bordner, K. A., Elwafi, H. M. \& Simen, A. A. Maternal separation with early weaning: A novel mouse model of early life neglect. BMC Neurosci. 11, 32 (2010).

52. Gardner, K. L., Thrivikraman, K. V., Lightman, S. L., Plotsky, P. M. \& Lowry, C. A. Early life experience alters behavior during social defeat: Focus on serotonergic systems. Neuroscience 136, 181-191 (2005).

53. Auth, C. S. et al. Differential anxiety-related behaviours and brain activation in Tph2-deficient female mice exposed to adverse early environment. Eur. Neuropsychopharmacol. 28, 1270-1283 (2018).

54. Sachs, B. D. et al. The effects of brain serotonin deficiency on behavioural disinhibition and anxiety-like behaviour following mild early life stress. Int. J. Neuropsychopharmacol. 16, 2081-2094 (2013).

55. Dringenberg, H. C., Hargreaves, E. L., Baker, G. B., Cooley, R. K. \& Vanderwolf, C. H. P-chlorophenylalanine-induced serotonin depletion-Reduction in exploratory locomotion but no obvious sensory-motor deficits. Behav. Brain Res. 68, 229-237 (1995).

56. Steigrad, P., Tobler, I., Waser, P. G. \& Borbely, A. A. Effect of p-chlorophenylalanine on cerebral serotonin binding, serotonin concentration and motor activity in the rat. Naunyn Schmiedebergs Arch. Pharmacol. 305, 143-148 (1978).

57. Millstein, R. A. \& Holmes, A. Effects of repeated maternal separation on anxiety- and depression-related phenotypes in different mouse strains. Neurosci. Biobehav. Rev. 31, 3-17 (2007).

58. Shalev, U. \& Kafkafi, N. Repeated maternal separation does not alter sucrose-reinforced and open-field behaviors. Pharmacol. Biochem. Behav. 73, 115-122 (2002).

59. Savignac, H. M., Dinan, T. G. \& Cryan, J. F. Resistance to early-life stress in mice: Effects of genetic background and stress duration. Front. Behav. Neurosci. 5, 13 (2011).

60. Wong, P. et al. Early life environmental and pharmacological stressors result in persistent dysregulations of the serotonergic system. Front. Behav. Neurosci. 9, 94 (2015).

61. Daniels, W. M., Pietersen, C. Y., Carstens, M. E. \& Stein, D. J. Maternal separation in rats leads to anxiety-like behavior and a blunted ACTH response and altered neurotransmitter levels in response to a subsequent stressor. Metab. Brain Dis. 19, 3-14 (2004).

62. Veenema, A. H., Bredewold, R. \& Neumann, I. D. Opposite effects of maternal separation on intermale and maternal aggression in C57BL/6 mice: link to hypothalamic vasopressin and oxytocin immunoreactivity. Psychoneuroendocrinology 32, 437-450 (2007).

63. de Kloet, E. R., Sibug, R. M., Helmerhorst, F. M. \& Schmidt, M. V. Stress, genes and the mechanism of programming the brain for later life. Neurosci. Biobehav. Rev. 29, 271-281 (2005).

64. Holmes, A. et al. Early life genetic, epigenetic and environmental factors shaping emotionality in rodents. Neurosci. Biobehav. Rev. 29, 1335-1346 (2005).

65. Anisman, H., Zaharia, M. D., Meaney, M. J. \& Merali, Z. Do early-life events permanently alter behavioral and hormonal responses to stressors?. Int. J. Dev. Neurosci. 16, 149-164 (1998).

66. Vetulani, J. Early maternal separation: A rodent model of depression and a prevailing human condition. Pharmacol. Rep. 65, 1451-1461 (2013)

67. Millstein, R. A., Ralpho, R. J., Yang, R. J. \& Holmes, A. Effects of repeated maternal separation on prepulse inhibition of startle across inbred mouse strains. Genes Brain Behav. 5, 346-354 (2006).

68. Shawn Tan, H.S.H., Anna Yoonsu Song, J. L., and Je, H. S. Maternal separation does not produce a significant behavioral change in mice. Exp Neurobiol. 26, 390-398 (2017).

69. Parfitt, D. B., Wells, J., Corriveau, E. A. \& Helmreich, D. L. Early life stress effects on adult stress-induced corticosterone secretion and anxiety-like behavior in the C57BL/6 mouse are not as robust as initially thought. Horm. Behav. 52, 417-426 (2007).

70. Parfitt, D. B., Walton, J. R., Corriveau, E. A. \& Helmreich, D. L. Early life stress effects on adult stress-induced corticosterone secretion and anxiety-like behavior in the C57BL/6 mouse are not as robust as initially thought. Horm. Behav. 52, 417-426 (2007).

71. Yadav, V. K. et al. A serotonin-dependent mechanism explains the leptin regulation of bone mass, appetite, and energy expenditure. Cell 138, 976-989 (2009).

72. Hernandez, S. et al. A family-based association study of the HTR1B gene in eating disorders. Revista Brasileira De Psiquiatria 38, 239-242 (2016).

73. Steiger, H. Eating disorders and the serotonin connection: State, trait and developmental effects. J. Psychiatry Neurosci. 29, 20-29 (2004).

74. Own, L. S., Iqbal, R. \& Patel, P. D. Maternal separation alters serotonergic and HPA axis gene expression independent of separation duration in c57bl/6 mice. Brain Res. 1515, 29-38 (2013).

75. Kriegebaum, C. et al. Brain-specific conditional and time-specific inducible Tph2 knockout mice possess normal serotonergic gene expression in the absence of serotonin during adult life. Neurochem. Int. 57, 512-517 (2010).

76. Lieb, M. W. et al. Effects of maternal separation on serotonergic systems in the dorsal and median raphe nuclei of adult male Tph2-deficient mice. Behav. Brain. Res. 373, 112086 (2019).

77. Weidner, M. T. et al. Identification of cholecystokinin by genome-wide profiling as potential mediator of serotonin-dependent behavioral effects of maternal separation in the amygdala. Front. Neurosci. 13, 460 (2019).

78. Lesch, K. P. \& Waider, J. Serotonin in the modulation of neural plasticity and networks: Implications for neurodevelopmental disorders. Neuron 76, 175-191 (2012).

79. Dubois-Dauphin, M., Barberis, C. \& de Bilbao, F. Vasopressin receptors in the mouse (Mus musculus) brain: Sex-related expression in the medial preoptic area and hypothalamus. Brain Res. 743, 32-39 (1996).

80. Bielsky, I. F., Hu, S. B., Ren, X. H., Terwilliger, E. F. \& Young, L. J. The Vla vasopressin receptor is necessary and sufficient for normal social recognition: A gene replacement study. Neuron 47, 503-513 (2005). 
81. Charles, R. et al. Introduction of the human AVPR1A gene substantially alters brain receptor expression patterns and enhances aspects of social behavior in transgenic mice. Dis. Model. Mech. 7, 1013-1022 (2014).

\section{Acknowledgements}

This study was supported by the German Research Foundation (DFG: CRC TRR58-A05 to KPL and WA 3446/2-1 to JW), the European Union's Seventh Framework Program (FP7/2007-2013) under Grant No. 602805 (Aggressotype), the Horizon 2020 Research and Innovation Program under Grant No. 728018 (Eat2beNICE), and the 5-100 Russian Academic Excellence Project (to KPL). BA was supported by a research grant of the German Academic Exchange Services (DAAD). This publication was supported by the Open Access Publication Fund of the University of Wuerzburg.

\section{Author contributions}

J.W., B.A. and K.P.L. designed and supervised the study. J.W. and B.A. performed and analyzed the experiments. T.W. and D.B. contributed mouse lines. J.W., B.A. and K.P.L. wrote the main part of the manuscript. All authors interpreted the results and reviewed the manuscript.

\section{Funding}

Open Access funding enabled and organized by Projekt DEAL.

\section{Competing interests}

The authors declare no competing interests.

\section{Additional information}

Supplementary Information The online version contains supplementary material available at https://doi.org/ 10.1038/s41598-021-83592-4.

Correspondence and requests for materials should be addressed to K.P.L. or J.W.

Reprints and permissions information is available at www.nature.com/reprints.

Publisher's note Springer Nature remains neutral with regard to jurisdictional claims in published maps and institutional affiliations.

(c) (i) Open Access This article is licensed under a Creative Commons Attribution 4.0 International

License, which permits use, sharing, adaptation, distribution and reproduction in any medium or format, as long as you give appropriate credit to the original author(s) and the source, provide a link to the Creative Commons licence, and indicate if changes were made. The images or other third party material in this article are included in the article's Creative Commons licence, unless indicated otherwise in a credit line to the material. If material is not included in the article's Creative Commons licence and your intended use is not permitted by statutory regulation or exceeds the permitted use, you will need to obtain permission directly from the copyright holder. To view a copy of this licence, visit http://creativecommons.org/licenses/by/4.0/.

(c) The Author(s) 2021 